\begin{tabular}{|l|l|l|l|l|l|}
\hline MUNIBE Antropologia-Arkeologia & $n^{\circ} 69$ & $93-121$ & DONOSTIA & 2018 & ISSN 1132-2217 • eISSN 2172-4555 \\
\hline
\end{tabular}

\title{
Los inicios del Neolítico en las tierras meridionales valencianas: a propósito de la Cova dels Calderons (La Romana, Alicante)
}

\author{
The beginnings of the Neolithic in the southern Valencian region: \\ on the Cova dels Calderons (La Romana, Alicante)
}

\begin{abstract}
PALABRAS CLAVES: Neolítico, cardial, postcardial, colonización, segmentación social, ríos Serpis, Clariano y Vinalopó. GAKO-HITZAK: Neolitikoa, kardiala, kardial-ostekoa, kolonizazioa, segmentazio soziala, Serpis ibaia, Clariano eta Vinalopó. KEY WORDS: Neolithic, cardial, postcardial, colonization, social segmentation, Serpis, Clariano and Vinalopó rivers.
\end{abstract}

\begin{abstract}
Francisco Javier JOVER MAESTRE(1), Palmira TORREGROSA GIMÉNEZ(1), Gabriel GARCÍA ATIÉNZAR(1), María PASTOR QUILES ${ }^{(2)}$, Alicia LUJÁN NAVAS ${ }^{(3)}$, Francisco Javier MOLINA HERNÁNDEZ ${ }^{(3)}$, Sebastián PÉREZ DíAZ ${ }^{(4)}$, Mónica RUIZ ALONSO ${ }^{(4)}$, José Antonio LÓPEZ SÁEZ ${ }^{(4)}$, Carles FERRER GARCíA ${ }^{(5)}$ y Carmen TORMO CUÑAT ${ }^{(5)}$
\end{abstract}

\section{RESUMEN}

El estudio del Neolítico en el Levante de la península Ibérica cuenta con una larga trayectoria investigadora, siendo bien conocido en algunos valles como el Serpis o el Clariano. La excavación de un buen número de yacimientos en cueva y al aire libre ha posibilitado que esta zona sea un referente destacado a escala peninsular y del Mediterráneo occidental. Sin embargo, otras cuencas fluviales muy cercanas como la del río Vinalopó no han contado hasta el momento con suficientes bases secuenciales para su caracterización. Las primeras propuestas, establecidas a partir de los restos materiales hallados en diversos yacimientos al aire libre y en cueva, habían llevado a considerar que el proceso de neolitización se iniciaría a finales del VI milenio cal BC, casi medio siglo después de la presencia de comunidades agrícolas a lo largo del río Serpis. El proceso de implantación neolítica en el Vinalopó debía explicarse, por tanto, como resultado de la expansión poblacional desde el Serpis. Sin embargo, nuevas excavaciones y estudios vienen a ampliar el abanico de posibles explicaciones.

Así, a propósito de las evidencias arqueológicas documentadas en la excavación de la Cova dels Calderons (La Romana, Alicante), se exponen nuevos datos sobre la ocupación neolítica, en especial sedimentológicos, paleobotánicos, arqueozoológicos y nuevas dataciones absolutas, que permiten reflexionar sobre el proceso de neolitización de las tierras meridionales valencianas y, más en concreto, de la cuenca del río Vinalopó. Ello permite configurar una nueva hipótesis que viene a considerar que la presencia de grupos neolíticos en dicho territorio es más antigua que lo planteado hasta la fecha. Esta hipótesis, a su vez, lleva a inferir dos nuevos escenarios posibles: o bien, que el momento de llegada de los primeros grupos neolíticos a las tierras del norte de Alicante fue más antiguo de lo propuesto, o bien que la procedencia planteada para las primeras poblaciones neolíticas del sur de Alicante no sea la hasta ahora considerada-origen en cuencas más septentrionales como la del Serpis-, siendo la vía sur la más probable.

\section{LABURPENA}

Iberiar penintsulako Levante aldean Neolitikoaren azterketak ibilbide luzea du ikerketari dagokionez, eta oso ezagunak dira haran batzuk, hala nola Serpis edo Clariano. Leizean eta aire zabalean aztarnategi kopuru handia induskatu direnez, eremu hori erreferente nabarmena da penintsula mailan eta mendebaldeko Mediterraneoan. Hala ere, oso gertu dauden beste ibai-arro batzuetan, Vinalopó ibaian, esaterako, ez dira orain arte karakterizatu ahal izateko nahikoa oinarri sekuentzial bildu. Aire zabalean eta leizean dauden aztarnategi ugaritan topatutako hondakin material ugaritatik abiatuta egindako lehen proposamenen arabera, uste izan da neolitizazio-prozesua cal BC VI milurte amaieran hasiko zela, Serpis ibaian zehar nekazaritzako komunitateen presentzia baino ia mende erdi geroago. Vinalopóko ezarpen neolitikoaren prozesua, beraz, Serpisetik populazioa zabaldu izanaren ondorioa dela uste da. Baina egindako indusketa eta azterketa berriek azalpen posibleak ugaritu dituzte.

Hala, Cova dels Calderons-eko (La Romana, Alacant) indusketan dokumentatutako ebidentzia arkeologikoak direla eta, okupazio neolitikoaren inguruan datu eta datazio absolutu berriak agertu dira, bereziki sedimentologikoak, paleobotanikoak eta arkeozoologikoak. Horrek guztiak Valentziako hegoaldeko lurretako, eta zehatzago, Vinalopó ibai-arroko neolitizazio-prozesuari buruz hausnartzea ahalbidetzen du. Hala, hipotesi berri bat eragin du: lurralde horretan talde neolitikoen presentzia izan zitekeen orain arte planteatutako data baino lehenagotik. Hipotesi horrek, era berean, bi egoera posible berri dakartza: alde batetik, lehen talde neolitikoak Alacant iparraldera proposatutako data baino lehen iritsi izana, edo beste alde batetik, Alacant hegoaldeko lehen populazio neolitikoetarako planteatutako jatorria ez izatea orain arte kontuan hartutakoa (iparralderago dauden lekuetatik etorri izana, adibidez Serpisetik), eta hegoaldeko bidea izatea probableena.

\footnotetext{
(1) Instituto Universitario de Investigación en Arqueología y Patrimonio Histórico. INAPH. Universidad de Alicante.

(2) Departamento de Prehistoria, Arqueología, Historia Antigua, Filología griega y Filología latina. Universidad de Alicante.

(3) Arqueólogos.

(4) Grupo de Investigación Arqueobiología, Instituto de Historia, C.S.I.C., Madrid.

(5) Museu de Prehistòria de València.
} 


\begin{abstract}
The study of the Neolithic in the Levant of the Iberian Peninsula has a long research trajectory, being well known in some river valleys such as Serpis or Clariano. The excavation of a large number of cave and open-air deposits has made this area an outstanding reference on a peninsular scale and in the western Mediterranean. However, other nearby river basins such as the Vinalopó basin have not yet had sufficient sequential bases for their characterization. The first proposals, established from the material remains found in various open-air sites and in caves, had led to consider that the process of neolithization would begin at the end of the sixth millennium cal BC, almost half a century after the presence of agricultural communities along the Serpis river. The process of Neolithic implantation in the Vinalopó had to be explained, therefore, as a result of the population expansion from the Serpis. However, new excavations and studies come to expand the range of possible explanations.

Regarding the archaeological evidence documented during the excavations at Cova dels Calderons (La Romana, Alicante), we present new data, especially sedimentological, paleobotanical, archeozoological and new absolute dates. These allow us to reflect on the neolithization process of the territories in the Southern Valencian region, specifically in the Vinalopó river basin. These data make possible to formulate a new hypothesis which considers that the presence of Neolithic groups in that territory would occur much earlier than it was considered to date. This hypothesis leads us to two new possible scenarios: either the arrival of the first Neolithic groups to the northern areas of Alicante occurred in earlier times, or the origin of the first Neolithic populations in the southern areas of Alicante is not what it has been thought to date -northern basins such as the Serpis river one-. Considering this, the southern route to access these areas seems the most possible option.
\end{abstract}

\section{INTRODUCCIÓN}

El proceso de neolitización en las tierras meridionales valencianas es bien conocido gracias a la amplia profusión de trabajos de investigación (García Puchol 2005; García y Jover 2011; Bernabeu y Martí 2014; García Puchol y Salazar 2017). En concreto, la cuenca del río Serpis cuenta con una dilatada trayectoria investigadora en la que se han llevado a cabo diversos programas de prospección territorial (Molina Hernández 2001; Bernabeu et al. 2008b; Pardo-Gordó et al. 2015), además de la excavación de un buen número de yacimientos en cueva y al aire libre (Martí 1977; Martí et al. 1980; Bernabeu et al. 2003; 2009; García Puchol y Aura 2006; Torregrosa et al. 2011; Soler Díaz 2012, entre otros). El resultado ha determinado la validación de una secuencia de ocupación por parte de comunidades neolíticas cuyos inicios se remontan a ca. 5600 cal BC, así como un proceso de ocupación territorial y desarrollo social y cultural de enorme importancia por su valor referencial a escala peninsular y del Mediterráneo occidental (Bernabeu y Martí 2014).

Por el contrario, otras cuencas fluviales situadas a escasos kilómetros de distancia, como es la del Vinalopó, no cuentan, por el momento, ni con bases estratigráficas ni con series radiocarbónicas de similar calidad y magnitud. Sin embargo, en los últimos años, se han efectuado algunos trabajos, aunque vinculados a actuaciones arqueológicas de salvamento más que a proyectos de investigación (Segura y Jover 1997; Fernández 1999; Soler y López 2001; Torregrosa y López 2004; García Atiénzar et al. 2006; Jover et al. 2014; Hernández et al. 2012; Barciela et al. 2014; Guilabert y Hernández 2014) que han permitido contar con las primeras bases estratigráficas. Las hipótesis propuestas sobre la dinámica del poblamiento vienen a señalar algunas diferencias con respecto a la secuencia reconocida en la cuenca del Serpis y otras cuencas aledañas como la del Clariano (García Borja 2017). Los primeros ejercicios de correlación vislumbran que valles como el del Vinalopó serían ocupados inicialmente en su cabecera y, por tanto, en tierras interiores alejadas de la costa, situadas en contacto con otras como la del Clariano, mientras que la colonización del resto del curso hasta su des- embocadura en el mar Medioterráneo se efectuaría con posterioridad, en momentos neolíticos más avanzados (Guilabert et al. 1999; García y Jover 2011; Jover y García 2014). Este proceso se podría explicar si aceptamos que las tierras meridionales valencianas, y en concreto cuencas como la del Vinalopó, fueron ocupadas en un proceso de expansión terrestre por parte de grupos neolíticos desde las cabeceras de los ríos Serpis y Clariano (Torregrosa y Jover 2016). Grupos que, a su vez, serían los descendientes directos de aquellos pioneros que arribarían a determinados puntos de las costas del Levante peninsular a través de la vía marítima (Zilhão 1993, 2001; Martí 2008) y que, posteriormente, iniciarían un proceso de expansión territorial desde la desembocadura de ríos como el Serpis, hasta su cabecera.

Atendiendo a lo expuesto, en este artículo presentamos los datos obtenidos de la excavación efectuada en la Cova dels Calderons (La Romana, Alicante) con el objeto de introducir nuevos elementos de discusión sobre dicho proceso, considerando nuevas posibilidades sobre los inicios y el origen del Neolítico en las tierras meridionales valencianas.

\section{LA COVA DELS CALDERONS (LA ROMANA, ALICANTE)}

\subsection{Situación y características}

La Cova dels Calderons se localiza al oeste del término municipal de La Romana (Alicante) (Fig. 1). Se ubica en una pared rocosa de la ladera izquierda de un barranco poco abrupto y de escasa vegetación a los pies de L'Alt de la Creu, punto más alto de la sierra Pelada. Este barranco desemboca en la rambla Honda, zona de paso entre la cubeta del Medio Vinalopó y el Altiplano de Murcia, situándose el punto costero más cercano a unos $35 \mathrm{~km}$ de distancia en línea recta.

El espacio geográfico donde se ubica la cueva es una zona de relieve medio, a caballo entre las provincias de Alicante y Murcia. Hacia su zona noroccidental se localizan las elevaciones montañosas más importantes de su entorno, destacando la sierra del Carche con $1.371 \mathrm{~m}$ snm, al igual que la sierra de Salinas. En el lugar donde se sitúa la Cova dels Calderons, el relieve, 


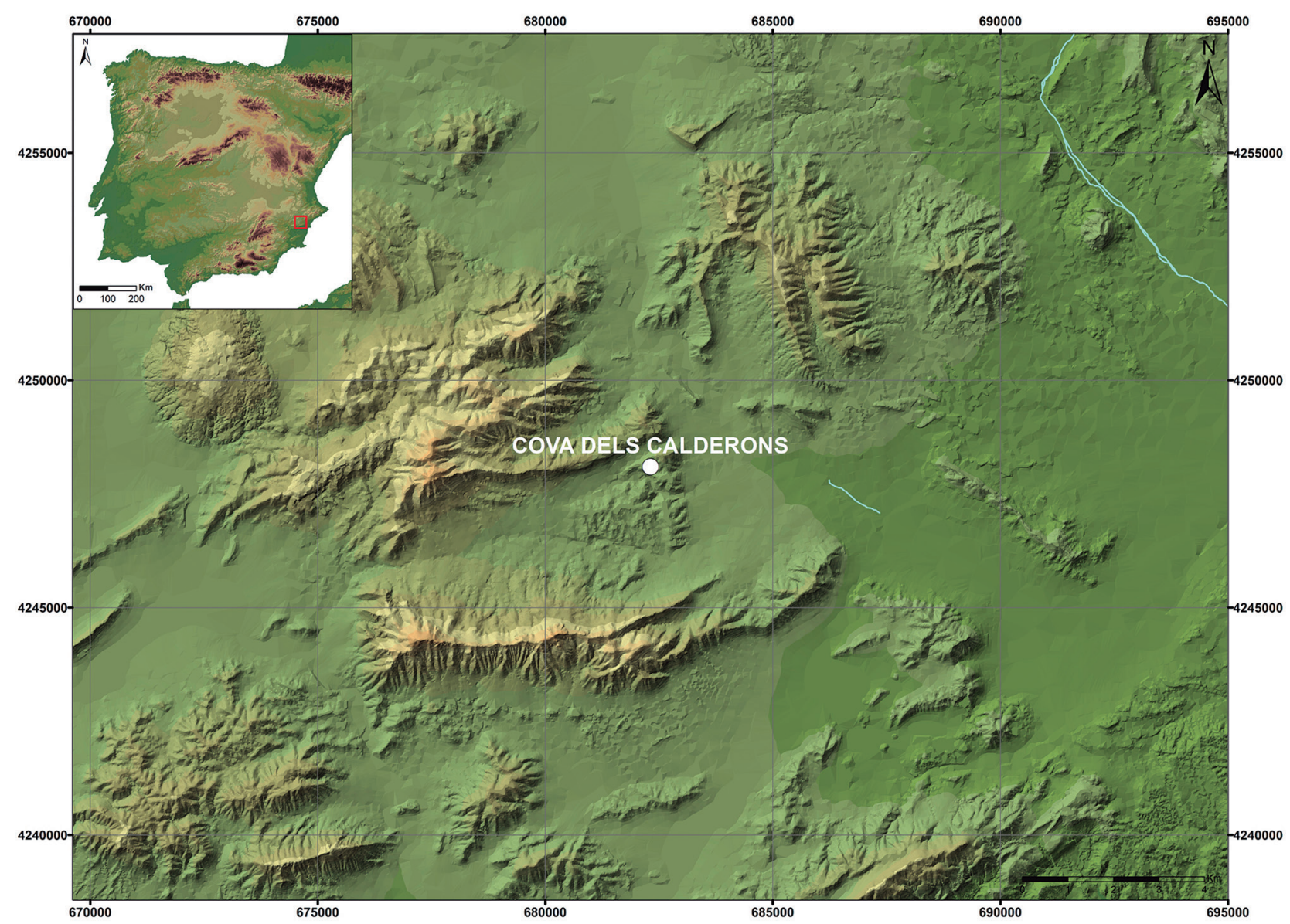

Fig. 1. Ubicación geográfica de la Cova dels Calderons (La Romana, Alicante). / Geographic location of Cova dels Calderons (La Romana, Alicante).

aun siendo montañoso, es más bajo, no alcanzando los $600 \mathrm{~m}$, a excepción de la sierra del Reclot con $1.043 \mathrm{~m}$ snm. La red fluvial es escasa, de tipo rambla y claramente efímera, acorde con un clima de tipo semiárido donde dominan las extensiones de esparto, aunque todavía se observan algunas concentraciones de pino carrasco en lo alto de las estribaciones montañosas.

La elevación montañosa de la Serra del Reclot y parte de la Pelada se caracteriza por calizas dolomíticas de color gris y aspecto masivo y litológicamente están formadas por micritas, biomicritas y pelmicritas. De igual modo, en ambas elevaciones también están representadas las calizas ricas en filamentos, tableadas en bancos, nodulosas y en general de color rosado (Gàllego et al. 1984: 26).

A media altura de la ladera occidental de la sierra Pelada se observan tres oquedades bajo un farallón calizo, separadas por unos $50 \mathrm{~m}$. La cueva principal es la que se encuentra a menor altitud durante el ascenso del barranco y la que presenta mayores dimensiones.
Se trata de una cavidad con la boca orientada al oeste, de planta triangular, de unos $22 \mathrm{~m}$ de longitud y en torno a $8 \mathrm{~m}$ de anchura máxima coincidiendo en la zona de acceso. También en esa zona es donde se observa la mayor altura de la cornisa, que decrece conforme nos adentramos hacia el fondo de la cueva (Fig. 2).

Tanto el interior de la cueva como la explanada frente a su acceso contienen un paquete sedimentario que ha sido objeto de numerosas remociones clandestinas de manera reiterada, al menos durante las últimas décadas del siglo XX. Parte de los materiales recuperados durante esas actividades ilegales están conservados en el Museo Arqueológico Municipal de Novelda y ya fueron objeto de estudio (Torregrosa y Jover 2016).

En julio de 2016 fue llevada a cabo una campaña de excavaciones arqueológicas autorizadas por la Dirección General de Cultura y Patrimonio de la Generalitat Valenciana ${ }^{1}$, cuyos resultados en relación con los niveles neolíticos son objeto de análisis en el presente trabajo. El interior de la cueva está rellenado por un

\footnotetext{
${ }^{1}$ La intervención arqueológica fue autorizada con fecha 10 de mayo de 2016 con expediente 2016/0185-A (SS.TT.: A-2016-073), siendo los directores Palmira Torregrosa Giménez y Francisco Javier Jover Maestre.
} 


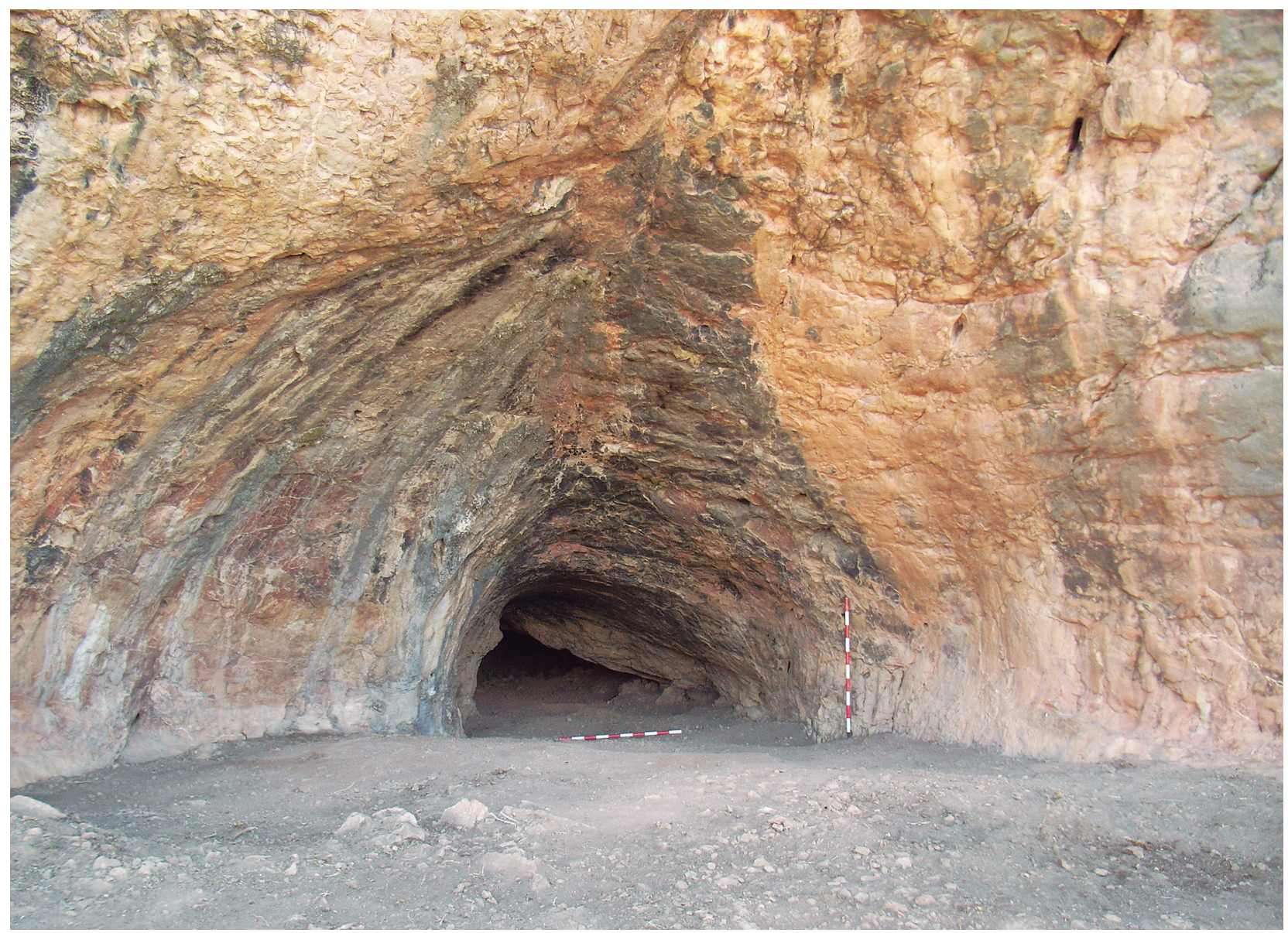

Fig. 2. Fotografía de la boca de la cavidad. / Photograph showing the opening of the cavity.

paquete sedimentario, sin desniveles acusados, cuya potencia estratigráfica va descendiendo de afuera a adentro. El paquete sedimentario superficial, de tono marrón oscuro con bloques y plaquetas calizas, de formación actual, desaparece a escasos metros de la boca, justo en el momento en el que se dificulta sobremanera la movilidad, debido a la estrechez y considerable reducción de la altura del techo. A partir de este punto se observa la existencia de un sedimento anaranjado-amarillento, con gran cantidad de bloques y plaquetas calizas, estéril a nivel arqueológico.

En definitiva, el área practicable de la cavidad se extiende hasta su zona media. Ello supone considerar una superficie útil máxima de unos $40 \mathrm{~m}^{2}$, a los que quizá habría que añadir algunos metros más si sumamos la explanada exterior de la cavidad (Fig. 3).

\subsection{La excavación}

Los primeros trabajos consistieron en la retirada de bloques calizos desprendidos de techo y paredes, así como la limpieza del área superficial de circulación, con la intención de determinar la ubicación más idónea para la actuación arqueológica. Tras esas labores de limpieza, se llevaron a cabo las primeras actuaciones topográficas -efectuadas por El Tossal Topografía-, que permitieron reproducir el alzado planimétrico y la fotogrametría del yacimiento mediante fotografía digital de alta resolución (Fig. 4). Estos mismos trabajos contribuyeron al establecimiento de la cuadriculación de la superficie de la cueva mediante la colocación de puntos estables visibles, constituyendo los ejes de referencia. De este modo, se concretó la ubicación del sondeo arqueológico, teniendo en cuenta para ello el lugar más idóneo y fácil para el desarrollo de los trabajos. El área de excavación arqueológica se emplazó en las cuadrículas 12E, 12F, 13E y 13F, situadas aproximadamente en la parte intermedia de la cueva, junto a la pared sur. Las dimensiones de cada cuadro eran de $1 \times 1 \mathrm{~m}$, con lo que el área total ascendió a $4 \mathrm{~m}^{2}$, además de algunos centímetros de cuadro parcial 13G. Durante el proceso de la excavación se reconocieron y diferenciaron diversas unidades estratigráficas -a partir de ahora UUEE-, en total 20, numeradas a partir de UE 100, correspondiendo ésta al nivel superficial y llegando hasta la UE 119, con la que se nombró a la base geológica compuesta por la roca caliza. Todo el material localizado in situ en las UUEE consideradas como fiables fue 


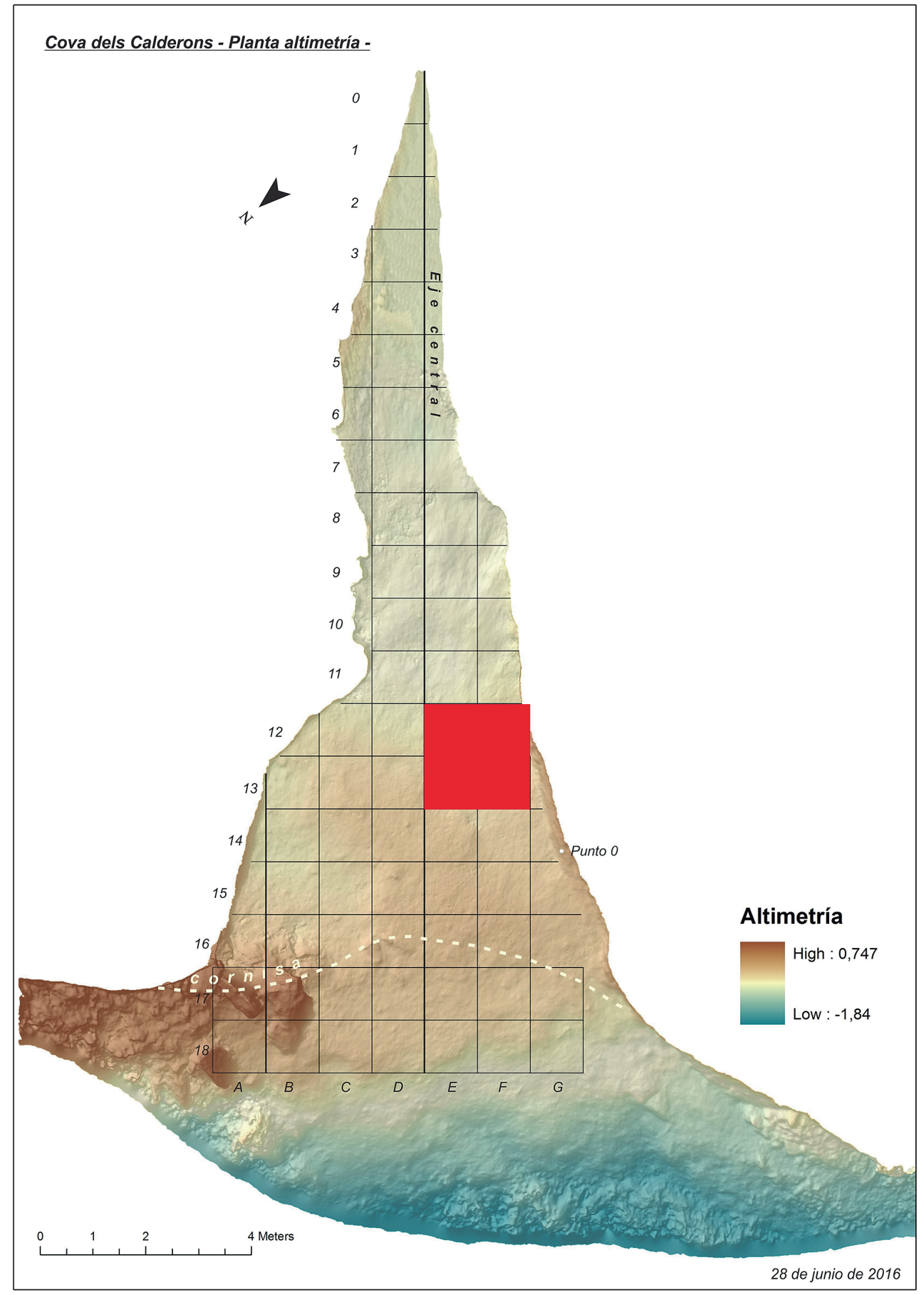

Fig. 3. Planta con indicación de los ejes de cuadriculación del espacio establecidos, señalando en rojo el sondeo efectuado. / Plant with indication of the established grid axes of the space, indicating in red the sounding carried out.

ubicado tridimensionalmente. La presencia de fosas de expolio, así como de madrigueras, no hicieron viable la introducción de subdivisiones en la cuadriculación para el material no retocado y de muy pequeño tamaño localizado en el proceso de cribado.

Si bien una parte importante de las unidades estratigráficas distinguidas corresponden a madrigueras y fosas de expoliación que habían afectado considerablemente a los estratos neolíticos, del Paleolítico supe- rior y del Paleolítico Medio, los niveles con información cronoestratigráfica correspondientes al Neolítico se localizaban en el techo del depósito sedimentario, en concreto las UUEE 103, 106, 107, 108, 109, 110 y 111.

\subsection{Estratigrafía y apuntes sedimentológicos}

Como acabamos de comentar, un número reducido de unidades estratigráficas se adscribieron al periodo 


\section{Cova dels Calderons - vistas en 3D -}
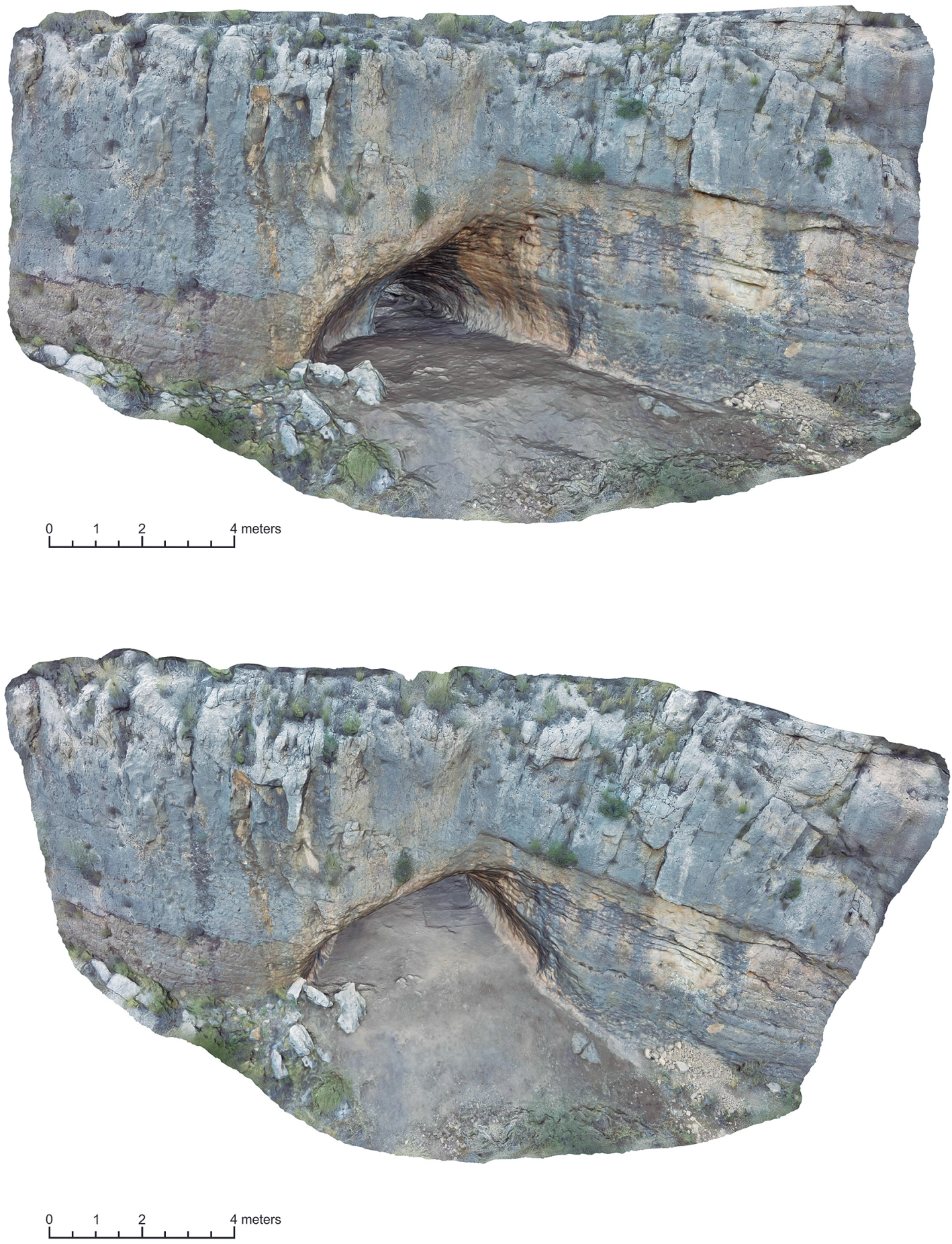

28 de junio de 2016

Fig. 4. Ortofoto desde distintos ángulos de la Cova dels Calderons. / Orthophotograph of Cova dels Calderons from different angles. 
neolítico. Todas ellas correspondían a estratos de relleno, que en ocasiones no se distribuían uniformemente por toda la superficie de excavación, detectándose únicamente en algunas de las cuadrículas, además de verse afectadas de distinta manera por madrigueras o remociones clandestinas que fueron aisladas durante el proceso de excavación (UUEE 104-105). En el proceso de excavación del paquete sedimentario correspondiente a la ocupación neolítica fueron diferenciadas varias UUEE, siendo el contacto entre ellas bastante difuso. Aunque presentaban la misma composición de limos de tono marrón grisáceo oscuro (4/3 10YR), con ligeros cambios hacia gris (6/1 10YR) o gris oscuro más intenso (5/2 10YR), la detección de un mayor o menor número en el porcentaje de cantos fue el criterio seguido para su diferenciación -de la UE 103 a la UE 111-. Únicamente en el caso de la UE 111 se decidió individualizarla sin atender a estos criterios, dado que se trataba del contacto erosivo con las UUEE infrapuestas adscritas al Paleolítico superior -UE 112- y Paleolítico Medio-UE 116- (Fig. 5).

La UE 103, de unos $12 \mathrm{~cm}$ de potencia y color gris (M2.5Y 5/1), correspondía a un estrato de sedimentación documentado en toda el área del sondeo y estaba compuesto por tierra arenosa suelta, con presencia de gravas y en algunos puntos de cenizas. Por su parte, la UE 106, con una potencia máxima de $8 \mathrm{~cm}$, solamente se registró de manera intermitente en las cuadrículas 12E, 13E y 13F. Estaba formada por un sedimento (M10YR 5/3) con limos, de textura compacta con presencia de gravas, cantos subangulosos, así como pequeñas lascas de caliza o costra calcárea.

En lo que respecta a la UE 107, localizada en todas las cuadrículas, aunque de manera muy tenue en la 13F, correspondía a un sedimento de limos de color grisáceo
(M10YR 6/1) con gravas y pequeñas lascas de caliza, algunas de ellas con signos de combustión -aunque en ningún momento se observaron indicios de posibles hogares-, y un porcentaje no muy alto de bloques. Entre los materiales recuperados destaca un bloque calizo, paralelepípedo a modo de plaqueta, con una de sus caras pulida por uso, junto a restos de carbones, piezas líticas y malacofauna marina. La potencia de este estrato variaba según las cuadrículas, alcanzando el mayor grosor en el ángulo noroeste del cuadro 13E.

Tanto la UE 108 como la UE 109 se asociaron a lentejones de pequeñas dimensiones, con sedimento de color anaranjado el primero y grisáceo el segundo, de forma ovalada, y localizados en el centro de las cuadrículas $12 \mathrm{E}$ y $13 \mathrm{E}$, respectivamente. Únicamente en la primera de ellas se registraron materiales arqueológicos -pequeñas esquirlas de fauna y alguna pieza malacológica-.

La UE 110, localizada exclusivamente en las cuadrículas $12 \mathrm{E}$ y $13 \mathrm{E}$, se caracterizaba por un estrato de relleno grisáceo (10YR 6/1) con limos, gravas y cantos subangulosos con signos de termoalteración -aunque de nuevo sin evidencias de hogares asociados-, presentando rasgos muy similares a la UE 107. Fue individualizada dado que se constataba por debajo de los lentejones anteriormente descritos.

Por último, la UE 111 se interpretó como la interfaz de contacto entre los niveles neolíticos y los paleolíticos donde el sedimento, del mismo color que la unidad superior, presentaba una consistencia ligeramente más suelta, con gravas y clastos.

Por tanto, este conjunto de UUEE -de la 103 a la 111- de poco más de $40 \mathrm{~cm}$ de potencia máxima (con un término medio de entre 15 y $25 \mathrm{~cm}$ ), estaba com-

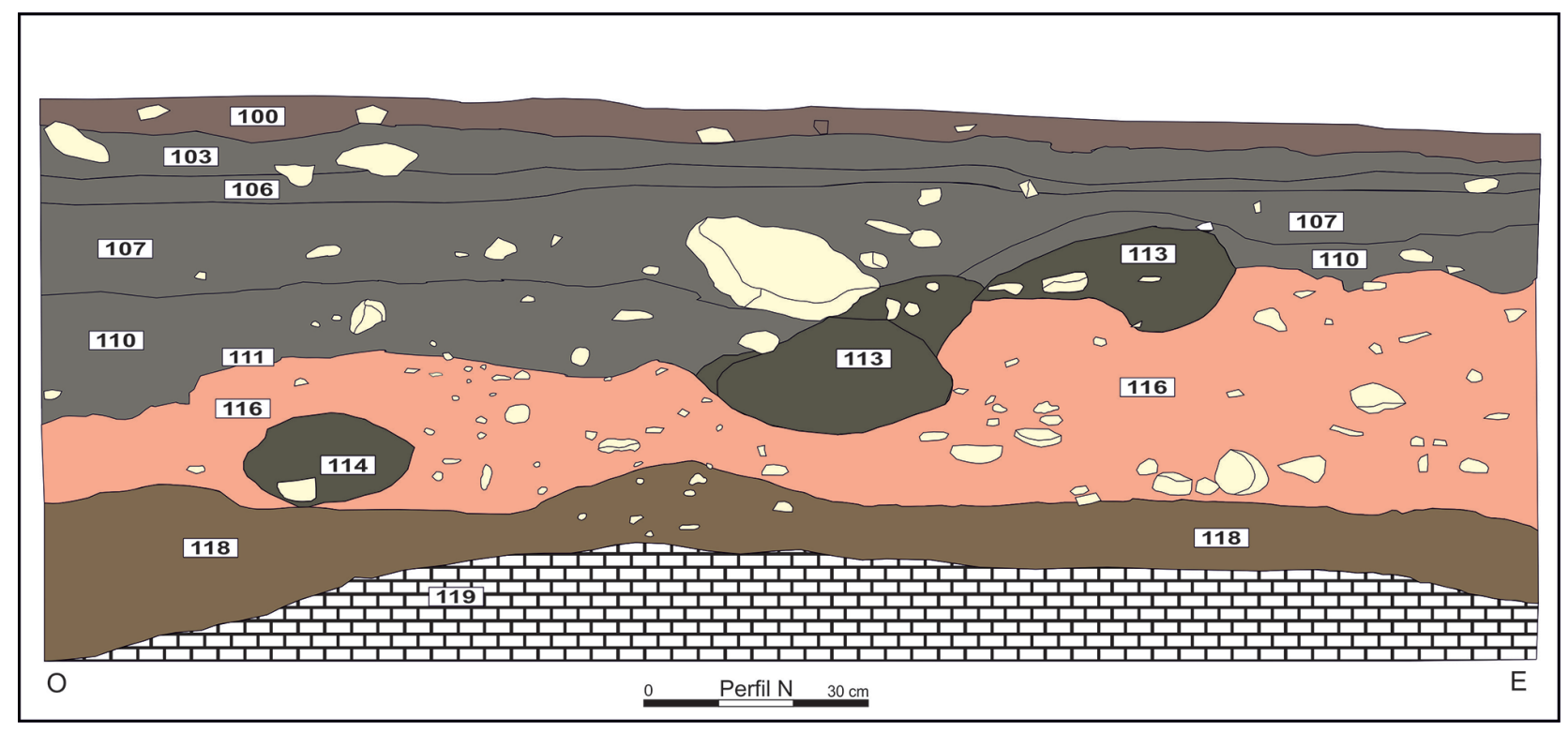

Fig. 5. Estratigrafía de la Cova dels Calderons en su perfil Norte. / Stratigraphy of Cova dels Calderons in its Northern profile 
puesto por limos con muy bajo porcentaje de gravas, más abundante en las UUEE finales -UUEE 106 y 103 y por pequeños cantos subangulosos cuyo porcentaje podía variar entre un $10-18 \%$ en la UE 107 y el $37 \%$ en la UE 110. En todos los casos, dichos cantos presentaban señales de termoalteración. En los muestreos sedimentológicos efectuados fueron documentados diversos porcentajes de conchuela procedentes de gasterópodos continentales, pudiendo destacarse sus altos niveles en la UE 107, así como la escasa incidencia observada en la UE 110.

En definitiva, este conjunto de estratos que sellan el depósito sedimentario, a diferencia de los basales, responden en gran medida a un aporte de fracción sedimentaria antropogénica. Estarían formados por componentes como limos, carbones y cenizas, derivados de las actividades humanas que utilizan el fuego de manera intensa, ya sea para actividades de preparación de alimentos, ya sea en la gestión ganadera del espacio, vinculado con el saneamiento de apriscos. La presencia de evidencias arqueológicas homogéneas de distinta naturaleza refuerza la frecuentación y presencia humana de este espacio en distintos momentos ya dentro del Holoceno.

\subsection{Estudios paleobotánicos}

El estudio palinológico se ha realizado sobre un total de 10 muestras de sedimento procedentes de otras tantas UUEE de los cuadros 12E, 13E y 13F. El tratamiento químico empleado para la extracción de los restos esporopolínicos se ha realizado en los laboratorios de Arqueobiología del Instituto de Historia en el Centro Ciencias Humanas y Sociales del Consejo Superior de Investigaciones Científicas, siguiendo la metodología estándar propuesta por Faegry e Iversen (1989), aunque sin acetolisis ${ }^{2}$ (Fig. 6). De todas las muestras analizadas, tan solo 5 han resultado positivas desde el punto de vista palinológico, ya que el resto no contenían la cantidad mínima de restos para considerarse como representativas. Por lo tanto, la caracterización del paisaje vegetal para los momentos neolíticos únicamente se puede efectuar atendiendo a los resultados de las muestras procedentes de las UUEE 107 y 108. Las muestras sedimentarias seleccionadas para su estudio palinológico no fueron tomadas del muestreo de un perfil, sino durante el proceso de excavación una vez definidas y delimitadas correctamente cada UE.

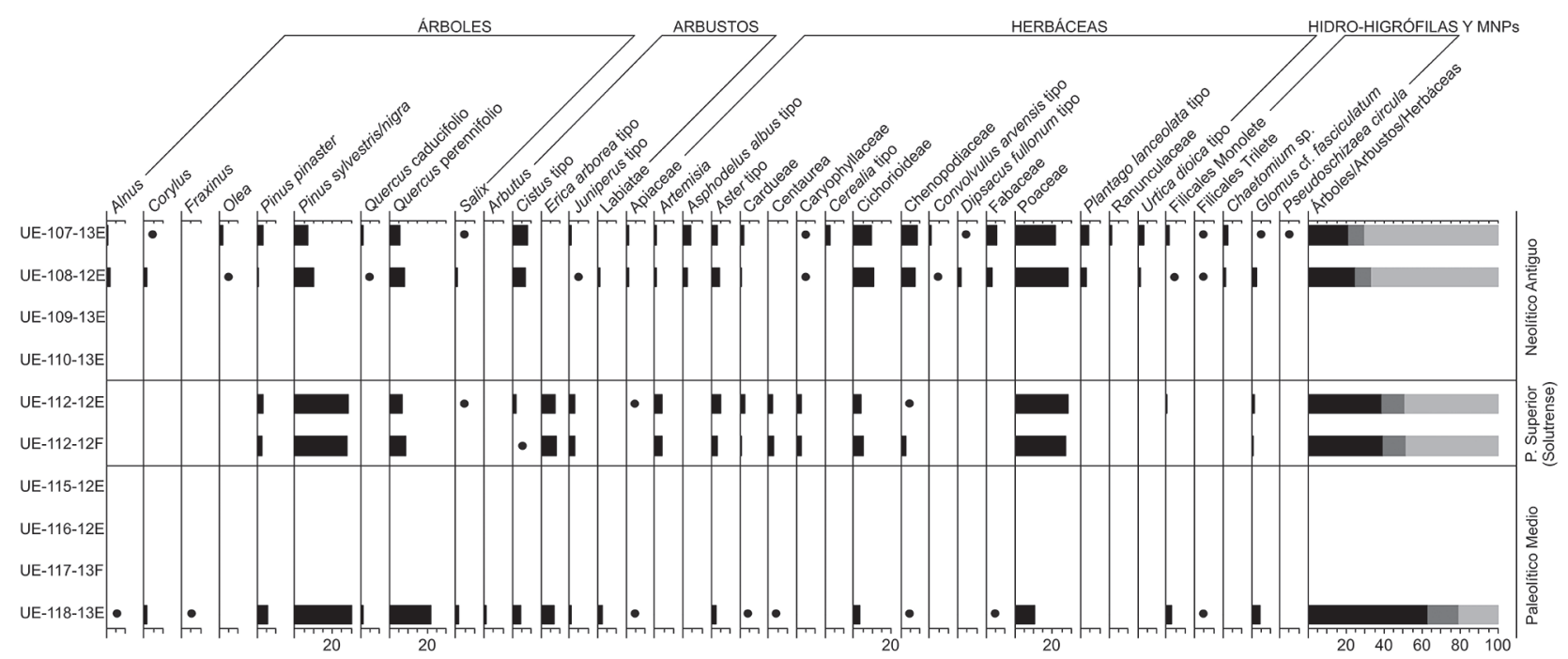

Fig. 6. Diagrama de taxones de pólenes identificados en las distintas UUEE. / Diagram of pollen taxa identified in the different stratigraphic units.

\footnotetext{
${ }^{2}$ Para la identificación de los palinomorfos se ha utilizado un microscopio óptico (modelo Nikon Eclipse 50i), con objetivos de 40x, 60x y 100x, este último con aceite de inmersión. Los granos de polen, las esporas y los microfósiles no polínicos se identificaron mediante la utilización de claves diagnósticas y atlas polínicos (Moore et al. 1991; Reille 1999), y de la colección de referencia del Grupo de Investigación Arqueobiología del CSIC. La identificación del morfotipo Cerealia se ha realizado de acuerdo a Beug (2004) y López Sáez y López Merino (2005). Los microfósiles no polínicos se identificaron según López Sáez et al. (1998), López Sáez et al. (2000) y van Geel (2001). En cada muestra se han identificado un mínimo de 200 pólenes procedentes de plantas terrestres (que constituyen la suma base polínica, SBP). Los porcentajes relativos de cada palinomorfo en cada muestra vienen referidos a la SBP. De ésta se excluyeron los palinomorfos de taxones hidro-higrófilos, esporas y microfósiles no polínicos, cuyos porcentajes se calculan también respecto a ella. El tratamiento de datos y su representación gráfica se ha realizado con los programas TILIA y TGview (Grimm 1992; 2004), y el software de imagen COREL DRAW. En la elaboración del histograma palinológico, como ya se ha comentado, se han excluido los taxa hidro-higrófilos, los microfósiles no polínicos, así como Aster, Cardueae y Cichorioideae, debido a que por su carácter zoófilo suelen estar sobrerrepresentados (Bottema 1975; López Sáez et al. 1998; 2000; 2003). El porcentaje relativo de estos palinomorfos excluidos se ha calculado respecto a la suma total.
} 
Por su parte, el análisis antracológico y carpológico ha sido efectuado a partir de diversas muestras ${ }^{3}$ preservadas en su totalidad por carbonización y recogidas a través de la flotación, cribado en seco y muestreo individual con referenciación in situ. Dado el grado de alteración detectado en el depósito, se consideró oportuno flotar en su integridad algunas UUEE singulares con mayor contenido orgánico -UUEE 108 y 109- y muestrear mediante su flotación el resto de UUEE fiables, seleccionando 40 litros por UE, además de efectuar el cribado en seco del sedimento restante. Junto a estos restos carbonizados se han localizado, de forma puntual, fragmentos de madera o semillas no carbonizadas, así como excrementos de animales que no se consideran de cronología antigua, sino intrusiones en la estratigrafía arqueológica, posiblemente relacionadas con las numerosas madrigueras detectadas, todas ellas correctamente individualizadas.

Los resultados obtenidos muestran algunos datos de interés a pesar del reducido número de evidencias (tabla 1). Desde el punto de vista palinológico, se aprecian algunos cambios paisajísticos con respecto a los momentos previos, correspondientes al Pleistoceno.
Los valores de polen arbóreo son los más reducidos de toda la secuencia, alcanzando un máximo de 24,8\%. En las UUEE neolíticas, los pinares de Pinus sylvestris/ nigra alcanzan valores algo bajos -10\%- con respecto a los valores del ámbito regional -más del 20\%-, a pesar de que la madera de pino sea la más utilizada, según muestra el análisis antracológico. La representación polínica de los Quercus perennifolios también retrocede ligeramente hasta un mínimo del 5,7\%, estando también presente de manera puntual en el registro antracológico, tanto taxones caducifolios como perennifolios. Aparece por primera vez el polen de Olea cuya frecuencia, junto con otros taxones como pistacea, Rhamnus/Phillirea, rosáceas y monocotiledoneas, muestra cierto incremento en el registro antracológico. Por otra parte, los taxones arbóreos caducifolios se recuperan con respecto a los niveles pleistocenos, reapareciendo Corylus y Quercus, al igual que el Alnus.

El impacto antrópico se detecta a través del incremento notables de determinadas comunidades, como son las nitrófilas (Dipsacus fullonum tipo, Aster tipo, Cardueae, Cichorioideae) y antropozoógenas (Chenopodiaceae, Plantago lanceolata tipo, Urtica dioica

\begin{tabular}{|c|c|c|c|c|c|c|c|c|c|c|c|c|c|c|c|c|}
\hline UUEE & \multicolumn{2}{|c|}{103} & \multicolumn{2}{|c|}{106} & \multicolumn{2}{|c|}{107} & \multicolumn{2}{|c|}{108} & \multicolumn{2}{|c|}{109} & \multicolumn{2}{|c|}{110} & \multicolumn{2}{|c|}{111} & \multirow[t]{2}{*}{ Total } & \multirow[t]{2}{*}{$\%$} \\
\hline Especies & $n^{\circ}$ & $\%$ & $n^{\circ}$ & $\%$ & $n^{\circ}$ & $\%$ & $n^{\circ}$ & $\%$ & $n^{\circ}$ & $\%$ & $\mathrm{n}^{\circ}$ & $\%$ & $n^{\circ}$ & $\%$ & & \\
\hline Arbutus & 4 & 26,7 & & & 6 & 1,7 & & & & & & & & & 10 & 1,08 \\
\hline Ilex aquifolium & & & & & & & & & & & 1 & 0,4 & & & 1 & 0,10 \\
\hline cf Juniperus & & & & & 1 & 0,3 & & & & & & & & & 1 & 0,10 \\
\hline cf Leguminosae & & & & & & & & & & & 1 & 0,4 & & & 1 & 0,10 \\
\hline Monocotiledoneae & & & & & 22 & 6,3 & 1 & 3,7 & & & 14 & 5,2 & 1 & 0,4 & 38 & 4,13 \\
\hline Olea sp. & 2 & 13,3 & & & 115 & 33 & 23 & 85,2 & 4 & 25 & 92 & 34,2 & 61 & 25,2 & 297 & 32,28 \\
\hline Pinus sp. & 6 & 40 & & & 59 & 16,9 & 3 & 11,1 & 12 & 75 & 121 & 45 & 154 & 63,6 & 355 & 38,58 \\
\hline Pistaceae & & & 1 & 50 & 40 & 11,5 & & & & & 8 & 3 & 4 & 1,7 & 53 & 5,76 \\
\hline Prunus sp. & 1 & 6,7 & & & 26 & 7,4 & & & & & 5 & 1,9 & 1 & 0,4 & 33 & 3,58 \\
\hline Prunus tipo armeniaca & 1 & 6,7 & 1 & 50 & & & & & & & 6 & 2,2 & & & 8 & 0,86 \\
\hline$Q i / c$ & & & & & 3 & 0,9 & & & & & 2 & 0,7 & 15 & 6,2 & 20 & 2,16 \\
\hline$Q s Q$ & & & & & & & & & & & 1 & 0,4 & & & 1 & 0,10 \\
\hline Rhamus/Phillirea & & & & & 31 & 8,9 & & & & & 16 & 5,9 & 6 & 2,5 & 53 & 5,76 \\
\hline Rosaceae & 1 & 6,7 & & & 30 & 8,6 & & & & & 1 & 0,4 & & & 32 & 3,47 \\
\hline Vitis & & & & & 16 & 4,6 & & & & & 1 & 0,4 & & & 17 & 1,84 \\
\hline TOTAL & \multicolumn{2}{|c|}{15} & \multicolumn{2}{|c|}{2} & \multicolumn{2}{|c|}{349} & \multicolumn{2}{|c|}{27} & \multicolumn{2}{|c|}{16} & \multicolumn{2}{|c|}{269} & \multicolumn{2}{|c|}{242} & 920 & 100 \\
\hline NO ID & & & & & 23 & & 12 & & 4 & & 17 & & 5 & & & \\
\hline
\end{tabular}

Tabla 1: Relación de especies vegetales identificadas en las UUEE neolíticas de la Cova dels Calderons. / List of plant species identified in the Neolithic stratigraphic units of Cova dels Calderons.

\footnotetext{
${ }^{3}$ En concreto, las correspondientes exclusivamente al Neolítico ascienden a un total de 40 litros de cada una de las UUEE 103, 106, 107, 110 y 111, así como a algo más de 10 litros de las UUEE 108 y 109. La identificación de los macrorrestos botánicos se ha realizado en los Laboratorios de Arqueobiología del Instituto de Historia en el Centro Ciencias Humanas y Sociales del Consejo Superior de Investigaciones Científicas. Los restos de madera se han examinado en un microscopio de luz incidente Leica DM 4000M (50x/100x/200x/500x) en sus secciones transversal, longitudinal radial y longitudinal tangencial. Se realiza la determinación mediante la comparación de las características anatómicas del material arqueológico con la colección de referencia de maderas modernas del laboratorio, así como consultando diferentes atlas de anatomía de la madera (Schweingruber 1978, 1990; Hather 2000; Vernet et al. 2001; García Esteban et al. 2002, entre otros).
} 
tipo). Además, se ha documentado el desarrollo de prácticas económicas productoras de alimentos, como indica la presencia de polen de cereal. Si bien sus valores son reducidos -2,8\%-, su escasa producción polínica y reducida dispersión permiten presuponer cierta cercanía de los campos de cultivo (Diot 1992; López Sáez y López Merino 2005). Además, la acción antrópica como factor modelador del paisaje se atestigua a través de la detección de indicadores de la ocurrencia de incendios, como son Asphodelus albus tipo y un microfósil no polínico -Chaetomium sp.-. Ambas evidencias, posiblemente, se refieran al uso del fuego como herramienta de apertura del paisaje. En la madera, junto a los anteriormente mencionados, se observan apariciones puntuales de leguminosas -Juniperus, Arbutus o llex aquifolium-, a veces representada por un único fragmento.

De este modo, los indicadores de condiciones secas reducen enormemente su presencia durante el Neolítico, mostrando un clima más húmedo que durante el Paleolítico superior. Sin embargo, además de las condiciones climáticas, el paisaje de esta fase también parece modelado por grupos humanos con economía productora que modificaron el entorno de la cavidad a través de su acción transformadora, básicamente con la apertura de campos de cultivo y por la acción ganadera.

\subsection{El estudio arqueozoológico}

La muestra recuperada para la ocupación neolítica asciende a 599 restos, de los que han podido identificarse un total de $393(65,6 \%)$, que incluyen tanto especies domésticas (2,5\%) como silvestres (63,1\%). Los restos indeterminados son 206 (34,4\%); entre estos, el
$51 \%$ corresponden a esquirlas y el $44,2 \%$ a mesomamíferos (tabla 2). El conjunto asciende a un número mínimo de individuos de 30.

El grupo de los ovicaprinos está representado por 11 restos - un fragmento craneal, cinco fragmentos molares, un incisivo primero, un incisivo segundo, un fragmento longitudinal proximal de metatarso y una epífisis distal de primera falange-. Dentro de este conjunto se han podido especificar cinco restos de oveja doméstica (Ovis aries): una hemimandíbula con el segundo y tercer premolar (Zeder y Lapham 2010), un astrágalo, una primera falange y dos segundas falanges. De todos estos restos se ha calculado un NMI de cinco, todos pertenecientes a individuos adultos.

Por lo que refiere a la fauna específicamente silvestre, el ciervo (Cervus elaphus) está representado por cuatro restos -un fragmento longitudinal de asta, un fragmento molar y dos fragmentos distales de primera falange-. Estos restos pertenecen a un mínimo de dos individuos, ambos adultos. También encontramos gato montés (Felis sylvestris) representado por dos restos.

La especie silvestre mejor representada es el conejo (NR 372), con un número mínimo de 18 individuos, de los cuales 13 corresponden a adultos y 5 a juveniles, estando representadas todas las partes anatómicas. El 48,9\% de estos restos consisten en pequeños fragmentos longitudinales de diáfisis que, debido a sus características de grosor y a la abundancia general en la muestra de restos de conejo, se han asignado a esta especie. Los elementos anatómicos más abundantes corresponden al miembro posterior $(30,4 \%)$, donde destacan los calcáneos, las tibias, las pelvis y los fémures. En segundo lugar, se encuentran los elementos

\begin{tabular}{|c|c|c|c|c|c|c|c|c|c|c|c|c|c|c|c|c|}
\hline UUEE & & & & & & & & & & & & & & & & \\
\hline Especies & NR & NMI & NR & NMI & NR & NMI & NR & NMI & NR & NMI & NR & NMI & NR & NMI & NR & NMI \\
\hline Ovis aries & 2 & 1 & & & & & & & & & & & 3 & 1 & 4 & 2 \\
\hline Ovicaprino & & & & & 1 & 1 & & & & & 1 & 1 & 9 & 1 & 11 & 3 \\
\hline Domésticos & 2 & 1 & & & 1 & 1 & & & & & 1 & 1 & 11 & 2 & 15 & 5 \\
\hline Cervus elaphus & & & & & & & 1 & 1 & & & & & 3 & 1 & 4 & 2 \\
\hline Felis sylvestris & & & & & 1 & 1 & 1 & 1 & & & & & & & 2 & 2 \\
\hline O. cuniculus & 100 & 5 & 6 & 1 & 24 & 3 & 56 & 3 & & & 19 & 2 & 167 & 4 & 372 & 18 \\
\hline Silvestres & 100 & 5 & 6 & 1 & 25 & 4 & 58 & 5 & & & 19 & 2 & 170 & 5 & 378 & 22 \\
\hline Especies determinadas & 102 & 6 & 6 & 1 & 26 & 5 & 58 & 5 & & & 20 & 3 & 181 & 7 & 393 & 27 \\
\hline Ave indeterminada & & & & & 1 & 1 & & & & & 2 & 1 & & & 3 & 2 \\
\hline Macromamífero & 2 & & & & & & 2 & & & & & & 1 & & 5 & \\
\hline Mesomamífero & 31 & & 2 & & 1 & & 12 & & 1 & 1 & 3 & & 41 & & 91 & 1 \\
\hline Micromamífero & 2 & & & & & & & & & & & & & & 2 & \\
\hline Esquirlas & 12 & & & & 13 & & 34 & & & & & & 46 & & 105 & \\
\hline Indeterminados & 47 & & 2 & & 15 & 1 & 48 & & 1 & 1 & 5 & 1 & 88 & & 206 & 3 \\
\hline TOTAL & 149 & 6 & 8 & 1 & 41 & 6 & 106 & 5 & 1 & 1 & 25 & 4 & 270 & 7 & 600 & 30 \\
\hline
\end{tabular}

Tabla 2: Número de restos (NR) y número mínimo de individuos (NMI) hallados en las unidades estratigráficas del Neolítico de la Cova dels Calderons. / Number of remains (NR) and minimum number of individuals (MNI) found in the Neolithic stratigraphic units of Cova dels Calderons. 
del miembro anterior (11,9\%) con más predominio de húmeros y ulnas.

Además, en la muestra han aparecido tres restos de aves -UUEE 106 y 110-. Se trata de fragmentos diafisarios que no conservan las epífisis, por lo que ha sido imposible una identificación específica y se han incluido en el grupo de los indeterminados. Del mismo modo, también se recuperaron dos restos de micromamíferos -UE 110- correspondientes a fragmentos de diáfisis que no han podido ser especificados.

En el análisis del conjunto han sido observadas diversas modificaciones, unas por la acción del fuego y otras de tipo carnicero. El 10,3\% de los restos se encuentran quemados. Entre estos, el $72,6 \%$ presenta termoalteraciones de color negro, el $21 \%$ de color blanco y el $6,4 \%$ de color marrón. Solo se han observado fracturas de origen carnicero en dos restos, uno correspondiente a un fragmento distal de primera falange de ciervo -UE 111-, cuya diáfisis presenta una fractura en fresco, y el otro a un fragmento longitudinal de diáfisis de macromamífero -UE 107- con una muesca de impacto en uno de sus bordes.

Como valoración final, podemos señalar que, a pesar de la riqueza faunística detectada en los niveles neolíticos, el 62,1\% de los restos pertenecen a conejo. Solo en parte podemos asegurar que estos restos fueron consumidos al determinarse en algunos de ellos marcas asociadas a carnicería y/o consumo. La existencia de diferentes alteraciones por exposición a fuentes de calor también puede estar relacionada con el cocinado de estos restos, aunque el estado de conservación de muchos de ellos impide valorar si se pudiera tratar de alteraciones postdeposicionales. Los otros taxones silvestres determinados corresponden a ciervo y gato montés, además de diferentes aves. Los únicos restos identificados de especies domésticas corresponden al grupo de los ovicaprinos, habiéndose reconocido únicamente oveja.

Este conjunto de características -predominio de oveja entre los domésticos y presencia notable de silvestres, entre ellos el conejo- son comunes en diferentes yacimientos neolíticos en cueva en el ámbito valenciano, como en el caso de la Cova de les Cendres (Iborra y Martínez-Valle 2009), la Cova de l'Or (Pérez-Ripoll 1980; 2016), la Cova de la Sarsa (Boessneck y Driesch 1980), l'Abric de la Falguera (Pérez-Ripoll 2006), la Cova d'En Pardo (Soler et al. 2013) o la cercana Cova de Sant Martí (Torregrosa y López 2004). Esta última, además, presenta una secuencia de ocupación similar a Calderons, aun cuando difiere ostensiblemente en sus características topográficas. Estos datos permiten considerar el uso de la cavidad como refugio ocasional relacionado con la actividad cinegética, pero también con el pastoreo, frecuentaciones que han sido vinculadas, en estos y otros contextos neolíticos, con el aprovechamiento estacional de las áreas de montaña próximas a los valles en los que se ubican las primeras aldeas campesinas (García Atiénzar 2006; 2009).

\section{LA CULTURA MATERIAL}

Los restos materiales documentados en el sondeo practicado se pueden considerar como escasos y poco diagnósticos en general, aunque sí guardan una enorme coherencia y homogeneidad. Entre ellos destaca la presencia de cuatro grandes tipos: un reducido lote de fragmentos cerámicos, elementos líticos tallados, objetos líticos pulidos y objetos malacológicos.

\subsection{Cerámica}

Se han documentado únicamente 27 fragmentos cerámicos de adscripción neolítica (tabla 3). Del estrato superficial también se recuperó un fragmento a torno con una banda horizontal pintada en color rojo, que podría orientar su adscripción hacia momentos de época ibérica, tal y como ha mostrado una de las dataciones absolutas.

\begin{tabular}{|c|c|c|c|}
\hline UE & BORDE & CUERPO & TOTAL \\
\hline $\mathbf{1 0 0}$ & 1 & 3 & 4 \\
\hline $\mathbf{1 0 3}$ & 1 & 1 & 2 \\
\hline $\mathbf{1 0 4}$ & & 1 & 1 \\
\hline $\mathbf{1 0 6}$ & & 1 & 1 \\
\hline $\mathbf{1 0 7}$ & 3 & 4 & 7 \\
\hline $\mathbf{1 1 0}$ & & 1 & 1 \\
\hline $\mathbf{1 1 1}$ & & 11 & 11 \\
\hline TOTAL & $\mathbf{5}$ & $\mathbf{2 2}$ & $\mathbf{2 7}$ \\
\hline
\end{tabular}

Tabla 3: Registro de fragmentos cerámicos realizados a mano procedentes de la excavación arqueológica. / Record of handmade ceramic fragments from the archaeological excavation.

El número mínimo de recipientes determinado es de 7 , aunque solamente contamos con elementos estructurales de 5 de ellos. Se han constatado 5 fragmentos de borde, 3 de ellos de orientación recta, 1 recto saliente y 1 cóncavo saliente. Se corresponden con recipientes de muy pequeño tamaño de tipo cuenco y olla, de escasa capacidad volumétrica, con labios convexos y pastas compactas con abundante desgrasante. Los desgrasantes son todos minerales, de tipo calizo preferentemente, a excepción de un fragmento de borde recto saliente procedente de la UE 107, que parece ser de tipo micáceo-lamproítico.

Por lo que se refiere a la decoración de las piezas, pocas son las muestras significativas en el cómputo total del repertorio. De los 27 fragmentos constatados, solamente 3 presentan decoración, destacando un fragmento de cuerpo de vasija con incisiones en forma de ángulos dispuestos en paralelo y otro con decoración peinada en su cara exterior (Fig. 7). 
UE 100-01
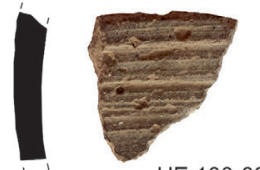

UE 100-02

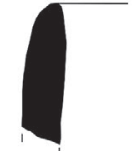

UE 103-53

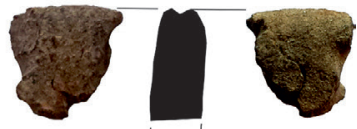

UE 107-01

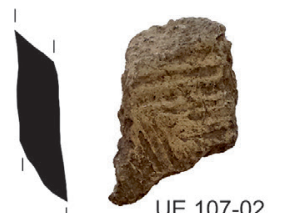

UE 107-02

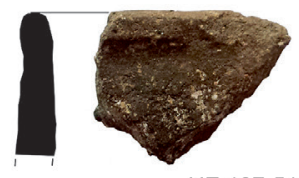

UE 107-51
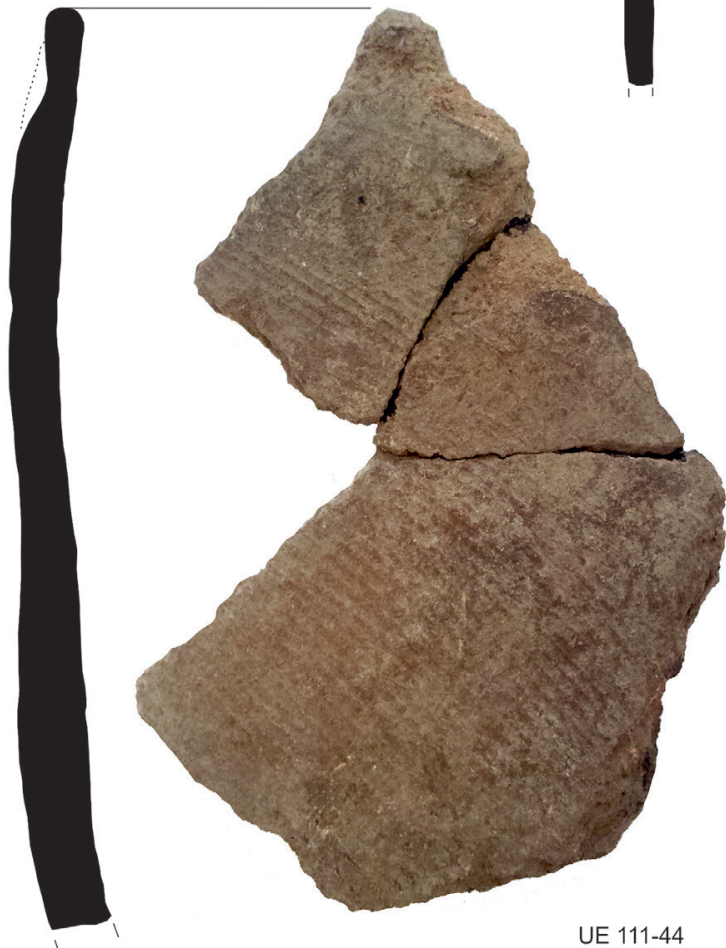

UE 111-44

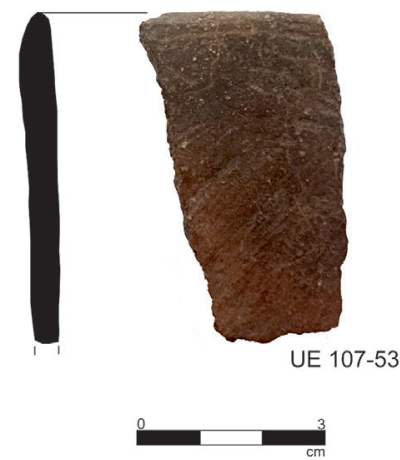

Fig. 7. Algunos fragmentos de bordes documentados en el proceso de excavación de distintas UUEE, destacando los que presentan tratamientos peinados. / Some ceramic rim fragments documented during the excavation process of different stratigraphic units, highlighting those that present combed treatments.

Si a estas evidencias unimos las recuperadas durante las actuaciones clandestinas (Torregrosa y Jover 2016), podemos definir el conjunto cerámico como escasamente significativo, caracterizado por la presencia de contenedores de reducido tamaño y volumetría, tanto de boca abierta como cerrada, cuencos, ollas y, probablemente, un cántaro. Cabe señalar la constatación de las técnicas decorativas de la incisión y el peinado, pudiéndose combinar ambos en un mismo recipiente, al igual que la impresión de instrumento, probablemente realizada mediante punzones de punta roma, también empleados en las incisiones. Resulta manifiesto, en relación con su valoración cronológica y cultural, que se trate de un conjunto cerámico homogéneo -a pesar de ser escaso- en el que están plenamente ausentes otras técnicas decorativas más diagnósticas (Bernabeu et al.

2011). Por tanto, con los pocos elementos registrados, el conjunto cerámico hallado podría vincularse en esencia con momentos del Neolítico antiguo postcardial.

\subsection{Materiales líticos}

El material lítico procedente de las UUEE de adscripción neolítica asciende a 485 piezas de las 1.101 recuperadas en su totalidad durante el proceso de excavación. Con la excepción de los soportes tallados en caliza -17-, cuarcita -1-, un canto de caliza, una roca de esquisto pulida correspondiente a un fragmento de pulsera o brazalete pulido y una roca metamórfica de grauvaca con una cara aplanada por el uso, de tipo afiladera, el resto corresponde a sílex. En este sentido, de los 17 soportes elaborados sobre caliza jurásica de 
origen local cabe indicar que todos ellos son de muy pequeño tamaño y en todos los casos corresponden a restos de talla. Todos proceden de los niveles Neolíticos o de formación actual, con la excepción de un fragmento de lámina que procede de la UE 112 adscrita al Paleolítico superior -aunque no se puede descartar que pueda tratarse de una filtración asociada a alguna de las múltiples madrigueras-. No hay ningún soporte calizo retocado, lo que puede estar indicando que la talla de la caliza fue un ejercicio puntual y, en ningún caso, una estrategia sistemática de uso y explotación de este tipo de roca con el fin de elaborar un utillaje específico.

La gestión y explotación sistemática de rocas estuvo centrada en la talla de una amplia variedad de sílex de tipo nodular, de diferentes tonalidades cromáticas y orígenes geológicos, aunque prácticamente en su totalidad procedentes de depósitos de conglomerados. La abundancia de neocórtex formados sobre superficies de abrasión indica su captación en depósitos detríticos. Estos sedimentos están muy bien representados en zonas próximas a la cavidad, como por ejemplo los conglomerados del Tortoniense-Villafranquiense o los depósitos aluviales del Pleistoceno del Vinalopó. La captación de recursos silíceos en estas unidades conglomeráticas se constata, por otro lado, a partir de la existencia en sus inmediaciones de un importante registro lítico de superficie como resultado de una intensa actividad de talla efectuada en diferentes periodos históricos (Molina 2016).

De este modo, de los 493 soportes, solamente 29 (5,88\%) presentan modificaciones en alguno/s de sus bordes como consecuencia de la aplicación de retoques (tabla 4). Se trata de un porcentaje de soportes retocados relativamente bajo, mucho más si consideramos que algunos son filtraciones de los niveles inferiores de ocupación de la cavidad -Paleolítico superior-.
En cuanto a la distribución espacial de los diferentes tipos de soportes, cabe destacar que las UUEE de adscripción neolítica son las que presentan una mayor cantidad de soportes laminares, en especial las UUEE 107 y 111. No obstante, también se debe destacar la buena representatividad de las lascas, así como de las astillas térmicas, debris y algún núcleo. La alta presencia de astillados térmicos se debe poner en relación con la existencia de hogares en algún lugar no muy alejado de dicho sondeo.

En este reparto de soportes por UUEE es indicativo, desde nuestro punto de vista, que las labores de talla del sílex, además de la caliza, fueron efectuadas en la propia cavidad. Los bloques de materia prima, una vez seleccionados, incluso previamente catados, habrían sido transportados a la cavidad para ser tallados en función de las necesidades de cada momento. El número de debris y lascas constatado, unido al hecho de estar acompañados de algún núcleo laminar, es un argumento firme para así considerarlo. Además, la presencia de lascas de $1^{\circ}, 2^{\circ}$ y $3^{\text {er }}$ orden, así como de algunos soportes laminares de $2^{\circ}$ y $3 e r$ orden en los niveles Neolíticos, sería otra prueba que vendría a confirmar dicha afirmación.

En cuanto a los restos de talla, y en relación con las lascas documentadas en la UE 107, cabe indicar que suelen presentar el talón liso, únicamente una lo tiene cortical. Son, en su mayoría, de $3^{\text {er }}$ orden -9-, pero también están representadas las de $2^{\circ}-4$ - y las de $1^{\circ}-1$-, habiendo sido obtenidas preferentemente mediante orientaciones unidireccionales. El tamaño medio suele ser de $23 \times 14 \times 5 \mathrm{~mm}$, siendo la lasca de mayor tamaño de $46 \times 25 \times 13 \mathrm{~mm}$. Similares características podemos señalar para los soportes lascares de la UE 111, donde, además de la talla unidireccional, se constata la mul-

\begin{tabular}{|c|c|c|c|c|c|c|c|c|c|}
\hline SOPORTES/UUEE & 100 & 101 & 103 & 104 & 106 & 107 & 110 & 111 & TOTALES \\
\hline Núcleo lascar & & 1 & 1 & & 2 (1 de caliza) & 1 & & 2 & 7 (1 de caliza) \\
\hline Núcleo laminar & & & & & & 1 & & & 1 \\
\hline Lasca & & 3 & $\begin{array}{c}18 \\
\text { (1 de cuarcita) }\end{array}$ & 4 & $\begin{array}{c}5 \\
\text { (1de caliza) }\end{array}$ & 14 ( 1 de caliza) & 9 & 18 & $\begin{array}{c}71 \text { (2 de caliza, } 1 \text { de } \\
\text { cuarcita) }\end{array}$ \\
\hline Fragmento lasca & & 2 (1 de caliza) & 15 (5 de caliza) & 3 & 1 & 8 (1 de caliza) & 3 & 16 & 48 (7 de caliza) \\
\hline Lámina & 3 & & 6 & & 1 & 4 & 1 & 14 & 29 \\
\hline Fragmento lámina & 1 & & 3 (1 de caliza) & 1 & 1 & 11 (1de caliza) & & 9 (1 de caliza) & 26 (5 de caliza) \\
\hline Laminita & & & 1 & & & 5 (1 de caliza) & & 2 & 8 (1de caliza) \\
\hline Fragmento laminita & & & & & & 2 (1 de caliza) & & 1 & 3 (1 de caliza) \\
\hline Debris & & 1 & 63 & 10 & 20 & 58 & 11 & 46 & 209 \\
\hline Chunk/indet. & & & 41 & 3 & 3 & 6 & 2 & 6 & 61 \\
\hline Piezas retocadas & 2 & & 7 & 2 & 4 & 5 & 3 & 6 & 29 \\
\hline TOTAL & 6 & 7 & 155 & 23 & 37 & 115 & 29 & 120 & $\begin{array}{c}493 \text { (17 de caliza y } 1 \text { de } \\
\text { cuarcita) }\end{array}$ \\
\hline
\end{tabular}

Tabla 4: Distribución general en las UUEE superficiales y de adscripción neolítica de restos líticos tallados sobre sílex. Se indica el número general de restos, haciendo constar entre paréntesis el número de soportes sobre caliza y cuarcita. / General distribution in superficial and Neolithic stratigraphic units of flaked lithic remains. The general number of remains is indicated, specifying the number of limestone and quartzite tools in parentheses. 
tidireccional y la centrípeta, siempre con talones lisos con dominio de las lascas de $3^{\text {er }}$ orden -16 - y reducida presencia de $2^{\circ}-4-$. Las dimensiones no varían con respecto a las obtenidas en la UE 107.

Por su parte, las láminas completas están presentes en las UUEE 103, 107 y 111. Las documentadas en la UE 107 presentan talones lisos, puntiformes en algunas laminitas, y preferentemente son de 3er orden, aunque también hay de $2^{\circ}$ orden $-2-$. Las dimensiones más habituales son de 27/23 x 12/11 x 4/3 mm. La estrategia de explotación detectada en los negativos de lascado muestra una tendencia 2-1-2. Estas mismas características se observan en una lámina procedente de la UE $110-21 \times 11 \times 3$ mm-, de talla unidireccional, así como en las documentadas en la UE 111, definidas por presentar talones lisos, de $2^{\circ}-6$ - y $3^{\text {er }}$ orden de ex- tracción -8-, talla unidireccional, con estrategias 1-2 y 1-2-3, y tamaños medios de $26 \times 15 \times 5$ mm que muestran formatos laminares cortos $y$ espesos.

En los soportes retocados -29- han sido diferenciados diversos grupos tipológicos (Fig. 8; tabla 5), incluyendo lascas y láminas retocadas, muescas y denticulados, geométricos, perforadores, raspadores, truncaduras, además de algunos soportes de clara adscripción al Paleolítico superior cuya presencia en estratos de adscripción neolítica se explica como consecuencia de las remociones y alteraciones que ha sufrido el depósito. Es el caso de la documentación de dos puntas y laminitas de dorso, láminas/laminitas o puntas escotadas, o de un perforador sobre lámina, documentadas en las UUEE 103, 107 y 110, o de dos puntas escotadas y una punta de pedúnculo y aletas

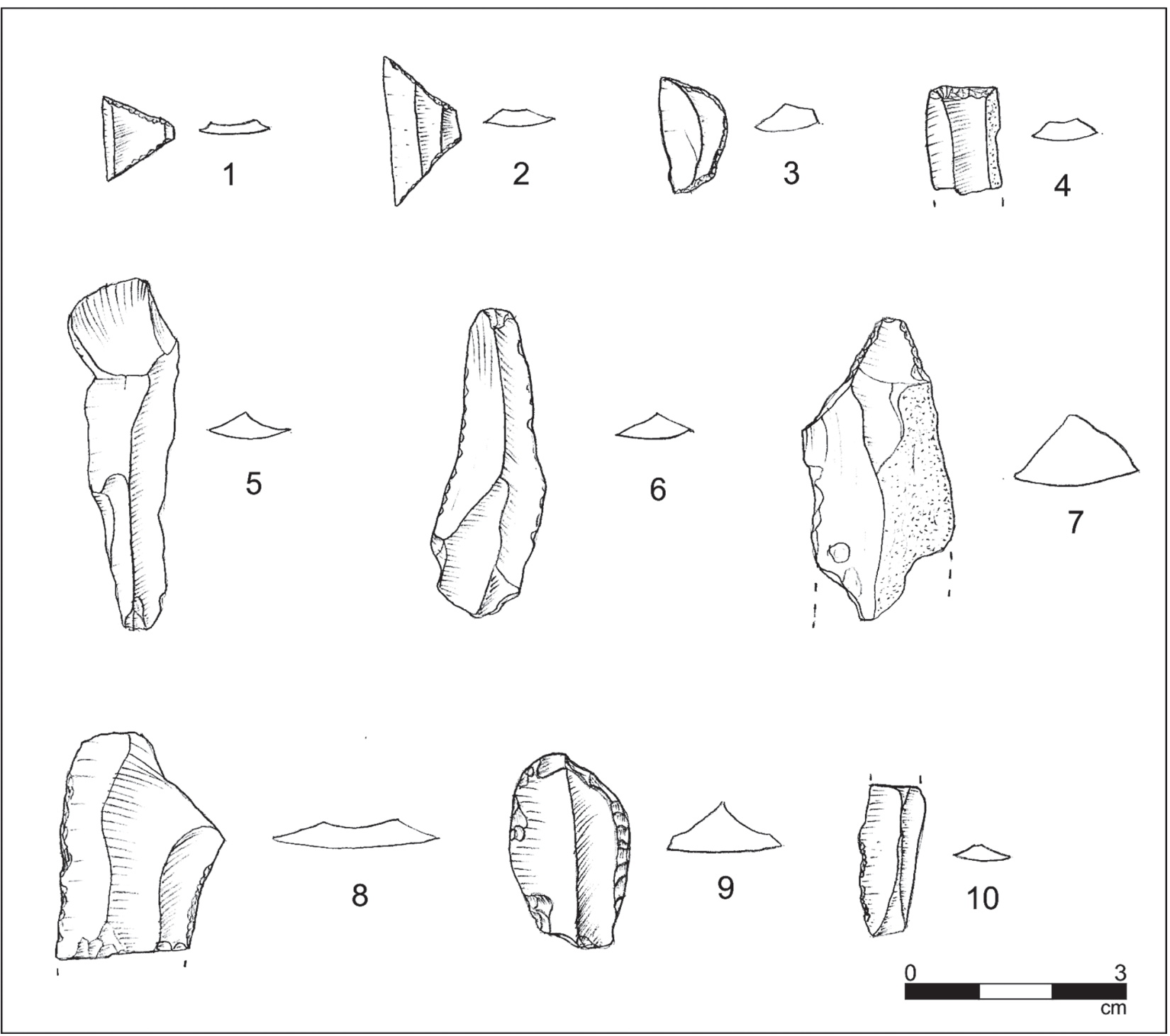

Fig. 8. Diversos soportes líticos tallados retocados. 1 y 2. Trapecios; 3. Segmento; 4. Truncadura; 5-8. Lámina con retoque marginales; 9. Raspador; 10. Lámina con retoque marginal. / Various flaked and retouched lithic pieces. 1 and 2. Trapezoids; 3. Segment; 4. Truncated flake; 5-8. Flake with marginal retouch; 9. Scraper; 10. Flake with marginal retouch. 


\begin{tabular}{|c|c|c|c|c|c|c|c|}
\hline TIPOS/UUEE & 103 & 104 & 106 & 107 & 110 & 111 & TOTALES \\
\hline Lámina borde abatido & & & & & 1 & 1 & 2 \\
\hline Lámina de retoque simple/marginal & 1 & 1 & 1 & 1 & & & 4 \\
\hline Laminita de dorso & 1 & & & & & & 1 \\
\hline Laminita/lámina/Punta escotada & & & & & 1 & 2 & 3 \\
\hline Lasca de retoque simple & 1 & & 2 & & & & 3 \\
\hline Lasca de borde abatido & & 1 & & & & 1 & 2 \\
\hline Denticulado sobre lasca & & & & & 1 & 1 & 2 \\
\hline Muesca sobre lasca & 1 & & & & & & 1 \\
\hline Punta de pedúnculo y aletas (Solutrense) & & & & & & 1 & 1 \\
\hline Punta de dorso & & & & 1 & & & 1 \\
\hline Perforador sobre lámina & 1 & & & & & & 1 \\
\hline Raspador sobre lámina & 1 & & & & & & 1 \\
\hline Raspador sobre lasca & & & & 1 & & & 1 \\
\hline Truncadura sobre lámina & & & & 1 & & & 1 \\
\hline Trapecio & 1 & & & 1 & & & 2 \\
\hline Segmento & & & 1 & & & & 1 \\
\hline TOTAL & 7 & 2 & 4 & 5 & 3 & 6 & 27 \\
\hline
\end{tabular}

Tabla 5: Variedad tipológica y distribución por UUEE de los soportes retocados. Obsérvese la presencia de tipos de adscripción paleolítica. / Typological variety and distribution by stratigraphic units of the retouched pieces. Note the presence of types of Paleolithic adscription.

de filiación solutrense en la UE 111. Por tanto, como consecuencia de la afección por diversos procesos postdeposicionales, en especial los biológicos y naturales de tipo erosivo, además de la acción humana, podemos considerar que los niveles neolíticos se encuentran alterados.

Por esta razón, junto a la presencia de los morfotipos habituales en los momentos neolíticos como son láminas con retoque simple marginal, láminas de borde abatido, dos trapecios de retoque abrupto -UUEE 103 y 107-, un segmento de retoque simple directo marginal -UE 106-, una truncadura sobre lámina, láminas y lascas con muesca, lascas de borde abatido y raspadores (Fortea 1973; García Puchol 2005; Juan Cabanilles 2009) -aunque no puede descartarse que los raspadores pudieran corresponder a los niveles del Paleolítico superior-, cabe añadir la presencia de tipos habituales en momentos del Solutrense avanzado, cuya matriz origen sería la UE 112 infrapuesta.

En definitiva, desde el punto de vista lítico, la presencia de geométricos -trapecios de retoque abrupto y segmentos de retoque simple (García Puchol 2005; Juan Cabanilles 2009)-, taladros y láminas con retoques marginales, un brazalete de esquisto pulido (Orozco 2016), junto a cerámicas inciso-impresas y peinadas, constituyen un conjunto de clara raigambre en el VI milenio cal BC.

\subsection{Malacofauna}

De más de medio millar de ejemplares malacológicos recuperados, el $94,08 \%$ procede de las UUEE de adscripción neolítica. En total, se documentaron 482 ejemplares, 479 de hábitat terrestre y tan sólo 3 ejemplares de origen marino. Por especies, cabe destacar la presencia de 477 ejemplares de Iberus g. alonensis, dos Ruminata decollata, un fragmento de Cerastoderma glaucum, una Trivia monacha y un fragmento de Dentalium vulgare. El predominio de especies terrestres encaja bien con lo observado en diferentes yacimientos de interior en los que predomina el Iberus alonensis, hecho que también se evidencia en contextos mesolíticos (Fernández López de Pablo y Gabriel 2016). Esta imagen contrasta con la observada en los yacimientos Neolíticos cercanos al litoral, donde los moluscos marinos son los consumidos de forma predominante (Luján y Rosser 2013).

En cualquier caso, el consumo bromatológico de estas especies no sería más que una parte complementaria de la dieta, práctica que, con el tiempo, será progresivamente descartada, pasando a destinarse estos recursos a una función ornamental y, en muy contadas ocasiones, a la producción de útiles u otro tipo de artefactos (Ruíz 1999).

El conjunto de elementos malacológicos marinos de la Cova dels Calderons está representado por especies ampliamente empleadas como adornos, documentándose con frecuencia en yacimientos de características y cronologías similares. El empleo de bivalvos como la Cerastoderma glaucum, con independencia de su mayor o menor manipulación antrópica, constituye una constante durante toda la Prehistoria reciente, como denota su presencia tanto en yacimientos de hábitat como en contexto funerarios. En el caso de los ejem- 
plares sobre gasterópodos señalados -un ejemplar de Trivia monacha o europea, especie especialmente valorada durante el Magdaleniense (Álvarez-Fernández 2010), y otro de Dentalium vulgare su valor recae en la confección de piezas ornamentales, aprovechando su reducida morfología como cuentas (Fig. 9). Este mismo uso se ha determinado en contextos próximos, como ocurre en el ejemplar de Trivia europea localizada en la Cova Sant Martí (Torregrosa y López 2004) o los numerosos ejemplares biperforados asociados a contextos eneolíticos de la zona. Lo mismo sucede con el Dentalium o Antalis vulgare, cuya concha tubulosa-cónica aparece empleada en forma de cuentas tubulares para
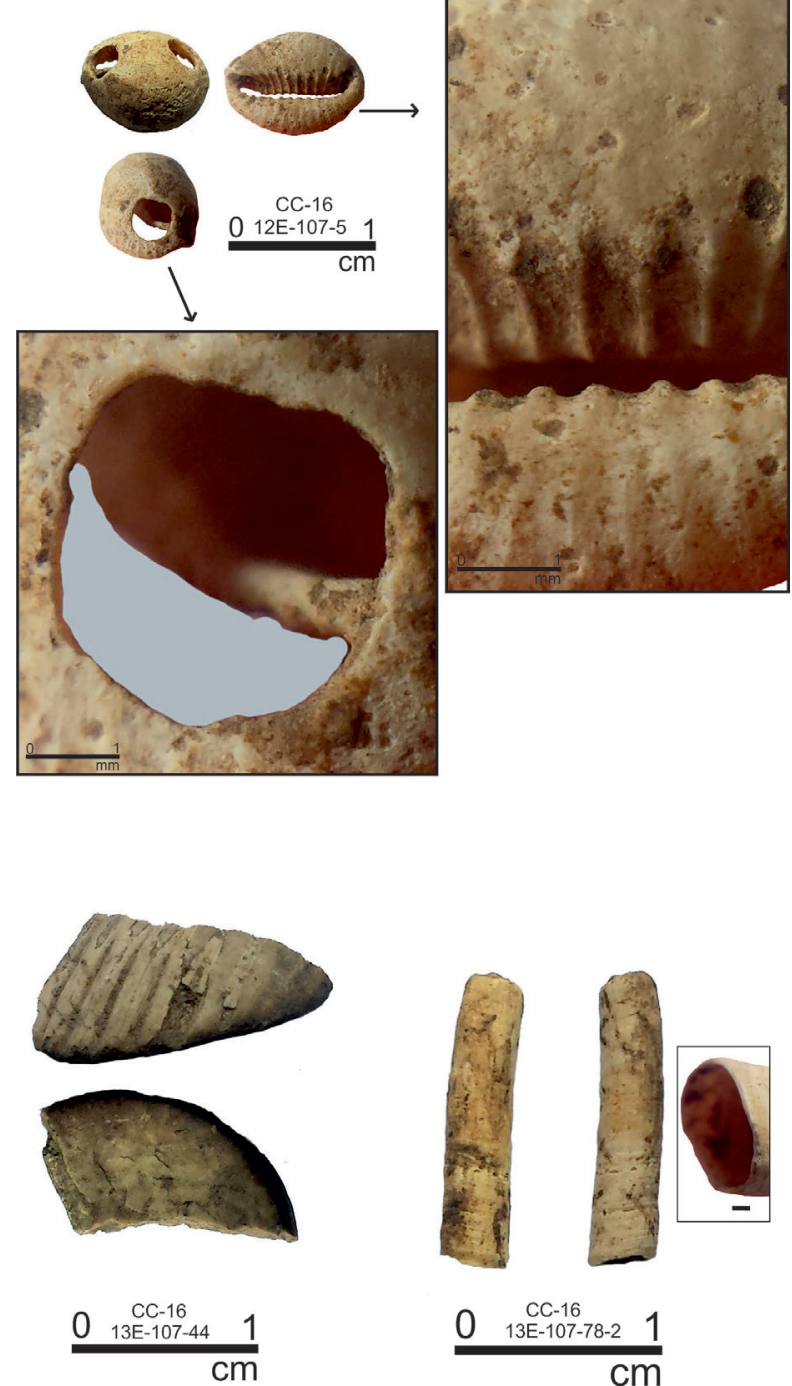

Fig. 9. Malacofauna marina. Arriba Trivia monacha, abajo a la izquierda e fragmento de Cerastoderma glaucum. Abajo a la derecha, el Dentalium vulgare. / Marine molluscs. Above, Monacha Trivia. Bottom left, fragment of Cerastoderma glaucum. Bottom right, Dentalium vulgare. la confección de collares y brazaletes, constatándose ampliamente en yacimientos neolíticos (Taborín 1979; Luján 2016). La presencia de caparazones marinos en contextos neolíticos, tanto en cueva como al aire libre, suele ser mucho más abundante y diversa en cuanto a especies que lo constatado en Calderons, aunque, a medida que nos alejamos de la costa, su número se reduce considerablemente, en directa relación con el hecho de prescindir de su aprovechamiento bromatológico. Por lo tanto, su empleo como adorno constituye la principal razón de su presencia en yacimientos alejados más de 20 km de la línea de costa, como es el caso de Calderons (Luján 2016).

En cuanto a los ejemplares del género Iberus $g$. alonensis, su inclusión en la dieta parece un hecho aceptado atendiendo a su elevada representación en yacimientos como la Cova de I'Or (Rico y Cantarino 1989) o la Cova Sant Martí (Torregrosa y López 2004), lo cual, atendiendo a las dimensiones de los ejemplares hallados en la Cova dels Calderons, consideramos factible, independientemente de que éstos posteriormente fueran reutilizados. Una parte de los caparazones pudieron ser reutilizados tras su ingesta, destinándose a la confección de adornos, lo que se atestigua en la práctica de orificios en su concha (Fig. 10). Estos orificios han sido detectados en 35 ejemplares de la Cova dels Calderons, pero también en casi una veintena de individuos en el Tossal de les Basses (Luján y Rosser 2013). La técnica de perforación aplicada a estos gasterópodos parece ser, a partir del estudio de las marcas existentes, el resultado de la aplicación de cierta presión mediante un elemento punzante romo, imprimiendo un movimiento rotatorio y continuo sobre sí mismo que permitiría la localización exacta del orificio sobre la superficie de la concha (Papí 1989; Pascual Benito 1994; Luján 2004).

\section{SOBRE LA CRONOLOGÍA DE LA OCUPA- CIÓN NEOLÍTICA}

Una vez identificadas las muestras óseas, palinológicas, carpológicas y antracológicas así como valorado el registro material recuperado en el proceso de excavación, se consideró necesario concretar la cronología de los diferentes momentos de ocupación ${ }^{4}$ de la cavidad. De los niveles con evidencias neolíticas fueron seleccionadas aquellas muestras que, en principio, presentaban signos de menor grado de alteración. De este modo, y ante la ausencia de semillas, se consideró datar tres muestras, dos óseas y un angiosperma de vida corta carbonizado, recuperados en distintas UUEE (tabla 6). Junto a éstas también fue seleccionada otra muestra ósea de la UE 112, correspondiente al Paleolítico superior.

\footnotetext{
${ }^{4}$ También de los niveles infrapuestos, aunque los resultados obtenidos de las muestras óseas seleccionadas hasta la fecha no han sido positivos por la ausencia de colágeno.
} 

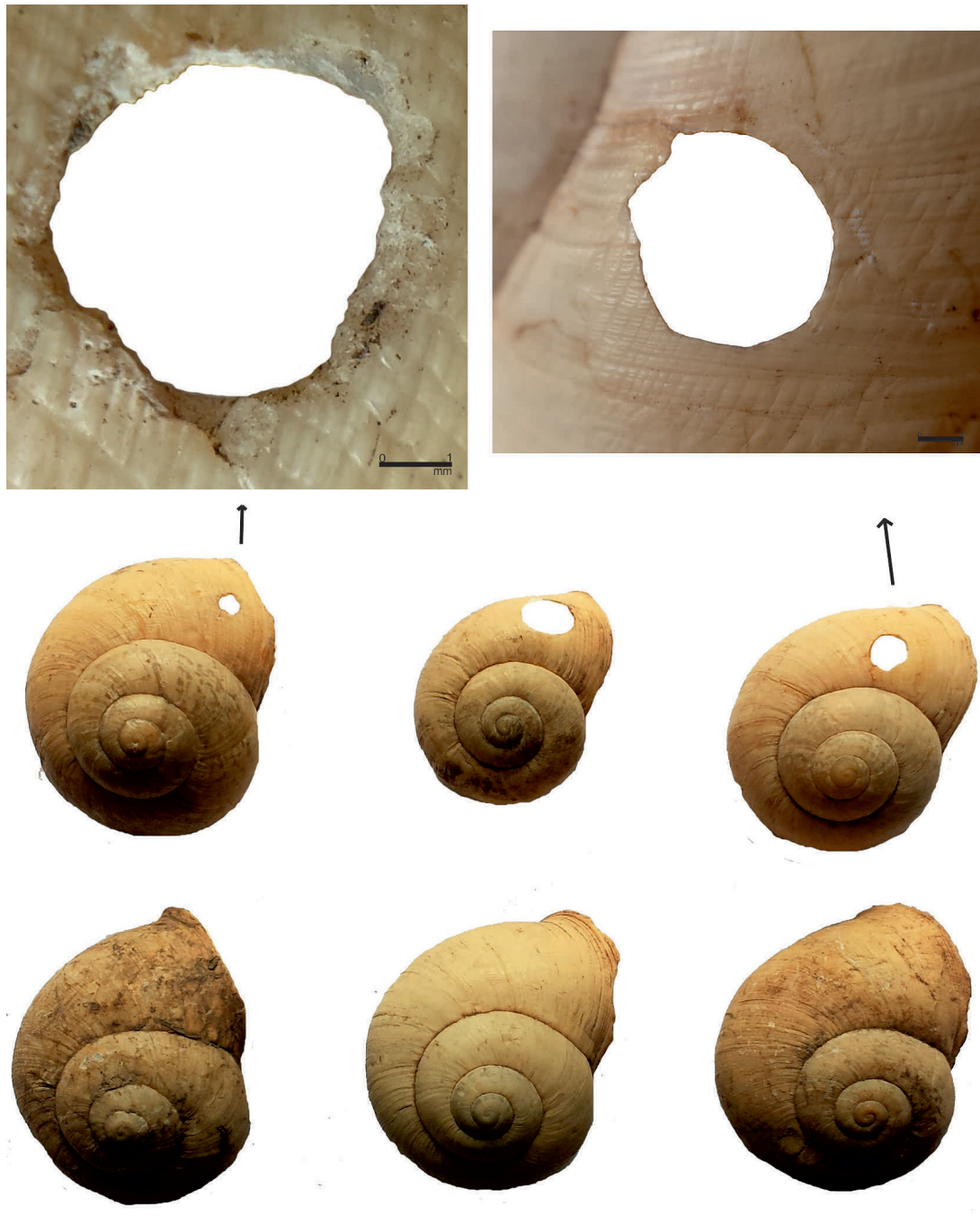

CC-16

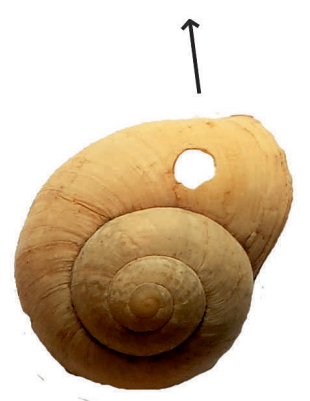

: 1
Fig. 10. Distintos ejemplares de Iberus alonensis perforados. / Different specimens of perforated Iberus alonensis.

\begin{tabular}{|c|c|c|c|c|c|c|c|c|c|}
\hline REF. LAB. & CONTEXTO & MUESTRA & $\mathrm{BP}$ & Cal BC 20 & $\delta 13 C(\%)$ & $\delta 15 \mathrm{~N}(\%)$ & $\mathrm{C}: \mathrm{N}$ & $\% \mathrm{C}$ & $\% \mathrm{~N}$ \\
\hline Beta-446587 & $\begin{array}{c}\text { CCAL-01. } \\
\text { CC-16. UE } 112\end{array}$ & $\begin{array}{l}\text { Fragmento óseo } \\
\text { de mesomamífero }\end{array}$ & Sin colágeno & & & & & & \\
\hline Beta- 446588 & $\begin{array}{c}\text { CCAL-02. } \\
\text { CC-16. UE } 111\end{array}$ & & $6560 \pm 30$ & $5555-5475$ & -17.3 & +4.1 & +3.3 & 41.57 & 14.58 \\
\hline Beta-448625 & $\begin{array}{c}\text { CCAL-02. } \\
\text { CC-16. UE } 111 \\
\text { Repetición del análisis }\end{array}$ & Ovis aries & $6590 \pm 30$ & $5615-5480$ & -17.6 & & & & \\
\hline Beta-451921 & CCAL-03. CC-16. UE 110 & Angiosperma & $2300 \pm 30$ & $400-360$ & -23.0 & & & & \\
\hline
\end{tabular}

Tabla 6: Relación de dataciones efectuadas en la Cova dels Calderons. / List of radiocarbon dates from Cova dels Calderons.

Aunque las muestras seleccionadas de las UUEE 110 y 111 se prometían como apropiadas para datar el conjunto material recuperado, los resultados obtenidos no lo posibilitaron, en tanto ambas dataciones presentaban problemas de distinta consideración. En el caso de la datación Beta-451921 (CCAL-03), la fecha obtenida a partir de un carbón de angiosperma no concuerda con el conjunto artefactual neolítico hallado ya que, grosso modo, corresponde al siglo IV a.C. Esta fecha puede relacionarse con un fragmento cerámico 
a torno decorado con una banda de pintura, de probable adscripción ibérica, documentado en superficie, evidenciando así que la cavidad fue frecuentada ocasionalmente durante esos momentos y que el registro material de los paquetes superiores de la cavidad se encuentra alterado y removido por factores biológicos y antrópicos.

Diferentes problemas plantean las dataciones obtenidas de la muestra CCAL-02 (Beta-446588 y Beta446625). Se decidió seguir los criterios habitualmente empleados para la selección de muestras a datar (Bernabeu 2006: 197), más aun teniendo en cuenta que estábamos trabajando en un contexto en cueva. Para ello fue tomada una muestra ósea asociada a un evento singular directo, identificada taxonómicamente como especie doméstica -fragmento de hemímandíbula de Ovis aries recuperada en la UE 111-y procedente de un estrato cuya materialidad asociada era claramente neolítica -en esta UE fueron documentados, entre otros, fragmentos de una vasija realizada a mano con tratamiento peinado en sus superficies-. Se realizó una labor diagnóstica -identificación taxonómica, tamaño, grado de fracturación, matriz sedimentaria adherida al hueso, coloración, etc.- con el objeto de concretar con mayor fiabilidad su adscripción a los niveles neolíticos y que no constituía una filtración de estratos inferiores. Con respecto a la taxonomía, todo indica que no hay razón alguna para dudar de que trata de un domesticado -Ovis aries- de procedencia y adscripción a momentos neolíticos, tratándose, además, de una pieza casi completa, lo que contrasta con el elevado grado de fracturación que muestra la fauna de los niveles paleolíticos (Fig. 11). Por otra parte, la matriz sedimentaria adherida a la muestra datada presentaba un carácter

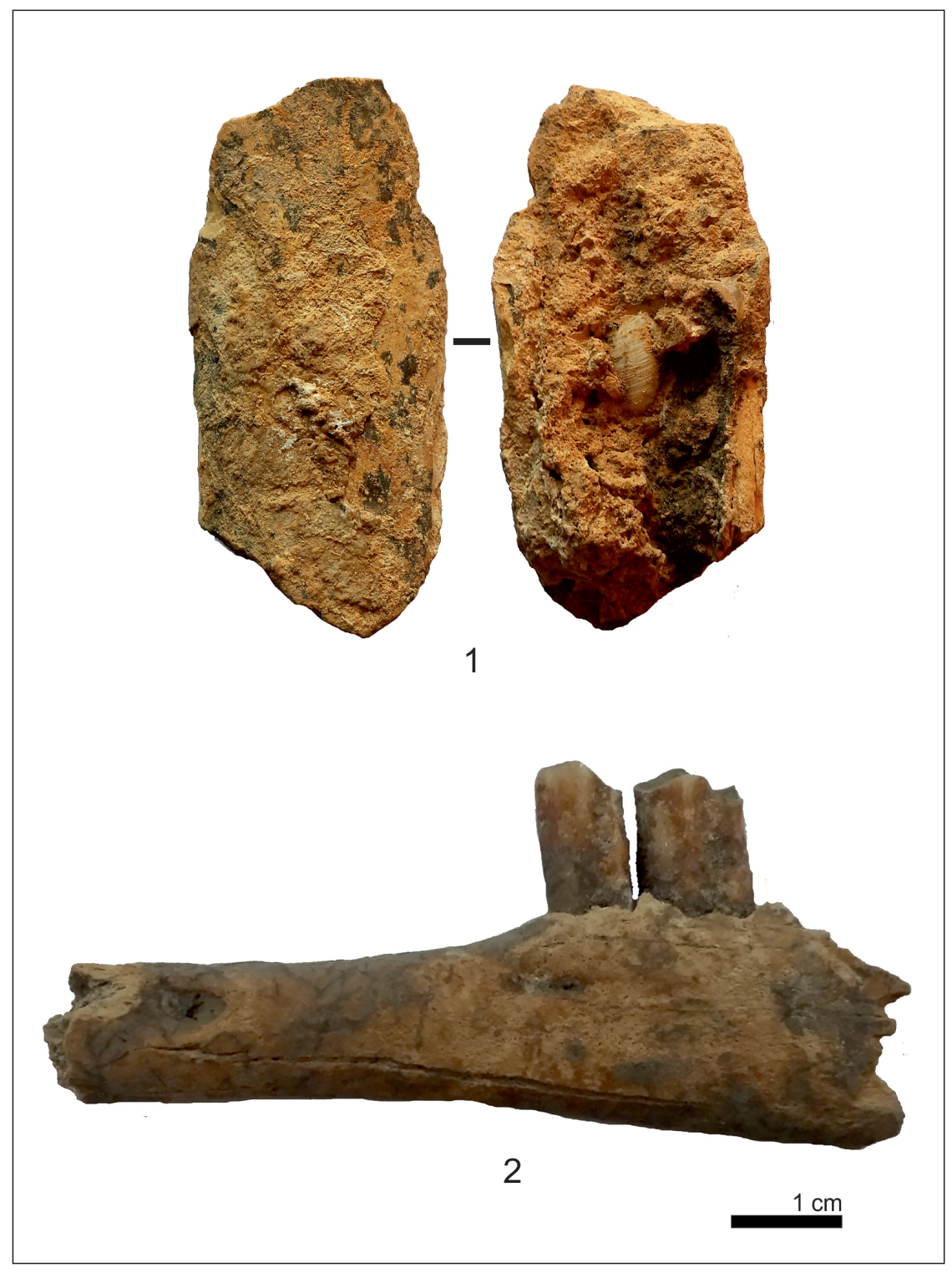

Fig. 11. Imagen de dos de las muestras seleccionadas para su datación. 1. CCAL-01. Fragmento de hueso largo de mesomamífero procedente de la UE 112, de adscripción Solutrense; 2. CCAL02. Mandíbula de Ovis aries procedente de la UE 111. / Image of two of the samples selected for dating. 1. CCAL-01. Fragment of long mesomammal bone from SU 112, of Solutrean affiliation; 2. CCAL-02. Ovis aries jaw from SU 111. 
limoso, frente al arcilloso de la procedente de estratos previos, así como una coloración marrón grisácea que contrastaba frente al amarillento/rosáceo de las unidades inferiores. Además, el propio resto óseo presentaba una pátina de tono marrón oscuro, muy diferente del amarillento de los infrapuestos. También se consideró el elevado movimiento de materiales entre estratos de contacto (Bernabeu et al. 1999), incluso dentro de una misma unidad sedimentaria. En este sentido, en la Cova dels Calderons no se han constatado niveles ni epipaleolíticos ni mesolíticos, así como tampoco materiales asociados a estos periodos ${ }^{5}$, que pudieran relacionarse con la datación obtenida.

El primer resultado obtenido (Beta-446588) mostró un balance cronológico bastante más antiguo -en torno a 500 años- que el que podríamos considerar a priori para el contexto material neolítico registrado, si nos atenemos a la secuencia y seriación cerámica propuesta para el ámbito regional (Bernabeu 1989; Bernabeu y Molina 2009). Por esta razón, se consultó al laboratorio sobre la anomalía del resultado obtenido y se nos comunicó la inexistencia de problemas en la muestra en tanto los rangos químicos y de conservación entraban dentro de los estándares de calidad del colágeno -\%C, $\% \mathrm{~N}, \mathrm{C}: \mathrm{N}-$ habituales para este tipo de muestras (Van Klinken 1999; Brock et al. 2013). Se nos ofreció la posi- bilidad de volver a efectuar un nuevo análisis de comprobación con la muestra de colágeno sobrante, cuyo resultado (Beta-446625) fue estadísticamente idéntico al anterior, situando la datación en torno al 5500 cal BC (Fig. 12). También fue solicitada la tasa de rendimiento del colágeno -collagen yield- ante la posibilidad de un problema de preservación del mismo. Desde el laboratorio se nos indicó que, lamentablemente, no fue realizada dicha medición. Sin embargo, dado que la ratio de C:N es perfecto y el \%C y el \%N están prácticamente a la mitad del rango normal, se puede considerar que el grado de conservación del colágeno sería excelente y el collagen yield normal ${ }^{6}$.

A este respecto, somos plenamente conscientes de los problemas y discusiones que durante décadas se vienen produciendo en relación con el origen y datación del primer Neolítico en la península ibérica (Bernabeu 2006; Martins et al. 2015; García Borja et al. 2018). Por todo lo expuesto, no encontramos argumentos que invaliden el resultado radiocarbónico obtenido, más aun si consideramos los valores ofrecidos por el laboratorio, además de la repetición de la datación. Por tanto, si establecemos como válidas las dataciones efectuadas sobre la muestra ósea procedente de la UE 111 (CCAL-027), y aplicamos la misma lógica deductiva que la seguida para la muestra CCAL-03, al considerar que

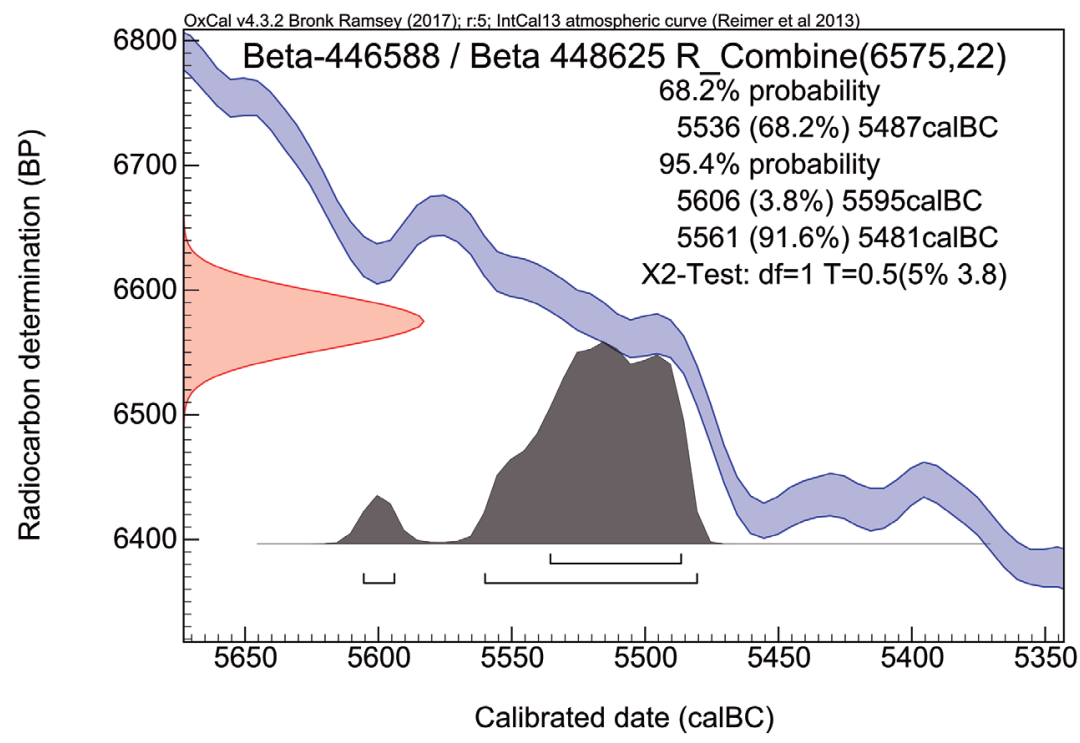

Fig. 12. Gráfica de la datación combinada correspondiente en la muestra CCAL-02. / Graph of the corresponding combined dating in the sample CCAL-02.

\footnotetext{
${ }^{5}$ Debemos recordar que la Cova dels Calderons presenta ocupaciones previas correspondientes al Solutrense (UE 112 y 117) y Paleolítico medio (UUEE 116 y 118). Debe indicarse, además, que en la UE 111 se documentó alguna pieza lítica desplazada correspondiente al Solutrense, cuestión lógica por otro lado en un contexto en cueva

${ }^{6}$ Según Ron Hatfield, director de calidad de Beta Analytic, "si el colágeno hubiese estado degradado debido a la meteorización, un sedimento muy ácido, el efecto del sol, el agua o la acción de los microbios, los valores de \% y \% N se habrían reducido considerablemente, afectando también al ratio C:N en un aumento o descenso más allá del rango aceptable, ya que este ratio se calcula basándose en los dos anteriores (C:N $=\% \mathrm{C} / \% \mathrm{~N} \times 1.167)$. El porcentaje de colágeno extraído no es el factor determinante para juzgar la calidad de una muestra ósea que se data por radiocarbono, sino que únicamente es uno de entre muchos factores cualitativos, que además es poco importante cuando se compara con otros datos".

${ }^{7}$ El test de significancia revela que ambos resultados son estadísticamente idénticos al 95\% (Xi2 (0,05): 3,84). El análisis estadístico combinado

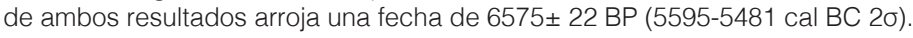


correspondería a un momento posterior en el que la cueva habría sido visitada -época ibérica-, tendríamos que plantear la posibilidad de que la cavidad fuese frecuentada por grupos humanos con domesticados, es decir, ya neolíticos, en un momento cercano a mediados del VI milenio cal BC, mucho antes que el/los momento/s al que deben corresponder la mayor parte de los materiales de adscripción neolítica documentados. No obstante, y siendo prudentes, somos conscientes de las limitaciones con las que ha sido abordada dicha investigación. No podemos olvidar que se trata de un sondeo y que la materialidad asociada a dicho resto óseo datado, a pesar de ser neolítica, no concuerda cronológicamente con la datación obtenida. Por lo tanto, esperamos que futuros trabajos puedan refrendar con restos materiales o, mejor aún, con algún horizonte bien conservado, el dato cronológico.

\section{DISCUSIÓN Y CONCLUSIONES}

La reciente excavación efectuada en la Cova dels Calderons (La Romana, Alicante) ha mostrado una secuencia de ocupación mucho más compleja de lo inicialmente esperado. Sobre niveles pleistocenos han sido detectados estratos holocenos que han mostrado cómo dicha cavidad fue ocupada o, más bien, frecuentada de forma puntual, desde el VI milenio cal BC hasta prácticamente la actualidad. Sin embargo, las características del registro neolítico evidencian una mayor densidad de restos materiales -cerámica y lítico tallado básicamente- correspondientes, según sus características, a momentos del horizonte postcardial definido para el ámbito regional (Bernabeu 1989; Bernabeu y Molina 2009).

Ahora bien, frente a este conjunto material, las dos dataciones obtenidas sobre restos óseos de un mismo individuo domesticado -Ovis aries- muestran una fecha combinada -Beta-446588 y Beta-448625: 6575 \pm 22 BP/5595-5481 cal BC 20- bastante más antigua que lo que el registro material podría hacer suponer (Fig. 12). Esta datación, de ser aceptada -y no hay motivo justificado para no hacerlo-, al igual que la datación de un angiosperma, serviría de argumento para considerar dos hechos de importancia para la interpretación y transcendencia de los datos obtenidos. En primer lugar, las dataciones obtenidas vendrían a evidenciar que los paquetes holocenos de la ocupación son un palimpsesto generado como consecuencia de la frecuentación humana de dicha cavidad, principalmente durante el Neolítico. Si no se hubiesen realizado dataciones absolutas, la presencia de un conjunto homogéneo de cerámicas inciso-impresas y peinadas nos hubiese hecho considerar que se trataría de una única ocupación efectuada durante momentos de la fase neolítica postcardial.

Y, en segundo lugar, la aceptación de la inferencia anterior implica replantear la hipótesis esbozada hace años sobre el proceso de neolitización de la cuenca del Vinalopó. De este modo, de aceptar la fecha obtenida, los primeros grupos campesinos, o al menos, ganaderos, comenzarían a ocupar dichas tierras mucho antes de lo considerado, al menos en algo más de 400 años con respecto a lo propuesto hasta el momento (Jover y García 2014; Torregrosa y Jover 2016).

En este mismo sentido, hace unos años fue publicada la datación obtenida en calle Colón 3 (Novelda) $-6410 \pm 40$ BP- (García Atiénzar et al. 2006), efectuada sobre una muestra singular de vida larga. Entonces, el hecho de ser una de las primeras fechas disponibles para la zona y el efecto de la madera vieja hizo considerarla como algo elevada para el conjunto material recuperado en el yacimiento. Esta fecha se asociaba a una estructura de combustión de tipo encachado en la cual fue documentado un fragmento con decoración impresa de instrumento. A varios metros de esta estructura aparecieron restos de otra estructura, totalmente desmantelada y asociada a materiales postcardiales. Por tanto, si reconsideramos el estado actual de la investigación, a la vista de los nuevos datos aportados por Calderons y de la revisión de los materiales de c/ Colón, ahora la fecha obtenida para este yacimiento parece más coherente dentro de un proceso que debió ser más temprano de lo inicialmente considerado. Es decir, estaríamos en condiciones de proponer que los primeros grupos neolíticos ya estarían frecuentando las tierras del Vinalopó hacia c. 5500 cal BC, casi de forma coetánea a lo documentado en valles como el del río Serpis o la cueva de Nerja en las costas malagueñas (García Borja et al. 2018: 13, tabla 1).

En cualquier caso, estas fechas son siempre similares o algo posteriores a las obtenidas en otros yacimientos neolíticos, tanto en cueva como al aire libre, ubicados en territorios septentrionales no muy alejados -las cuencas del Serpis y del Xaló- (Bernabeu et al. 2017; García Puchol et al. 2017a, 2018). El conjunto de dataciones disponibles para estas cuencas (tabla 7; Fig. 13) permite inferir que la presencia -que no su pleno afianzamiento- de comunidades neolíticas en cuencas como la del Serpis, situadas al norte del Vinalopó, tuvo que comenzar con anterioridad al $6660 \mathrm{BP}$, probablemente entre ca. 6800-6700 BP -en fechas convencionales- (Fig.14). Las excavaciones emprendidas en yacimientos como la Cova d'en Pardo o Mas d'Is así lo atestiguan. En un muy breve periodo de tiempo aquellos primeros grupos agropecuarios se irían consolidando en las tierras del norte de Alicante y sur de Valencia (García Atiénzar 2010a; García y Jover 2011; Jover y Torregrosa 2011), gestando a su vez un rápido proceso de expansión y colonización de nuevas tierras, en especial, hacia las meridionales.

En otras zonas de las costas mediterráneas de la península ibérica también se documenta la presencia de grupos neolíticos en fechas similares. Es el caso del Llobregat, con yacimientos como Les Guixeres, cuya primera presencia neolítica se data en $6655 \pm 45 \mathrm{BP}$ -OxA-26068; 5643-5507 cal BC 20; Oms et al. 2014o de zonas más meridionales, como las costas mala- 
OxCal v4.3.2 Bronk Ramsey (2017); r:5 IntCal13 atmospheric curve (Reimer et al 2013)

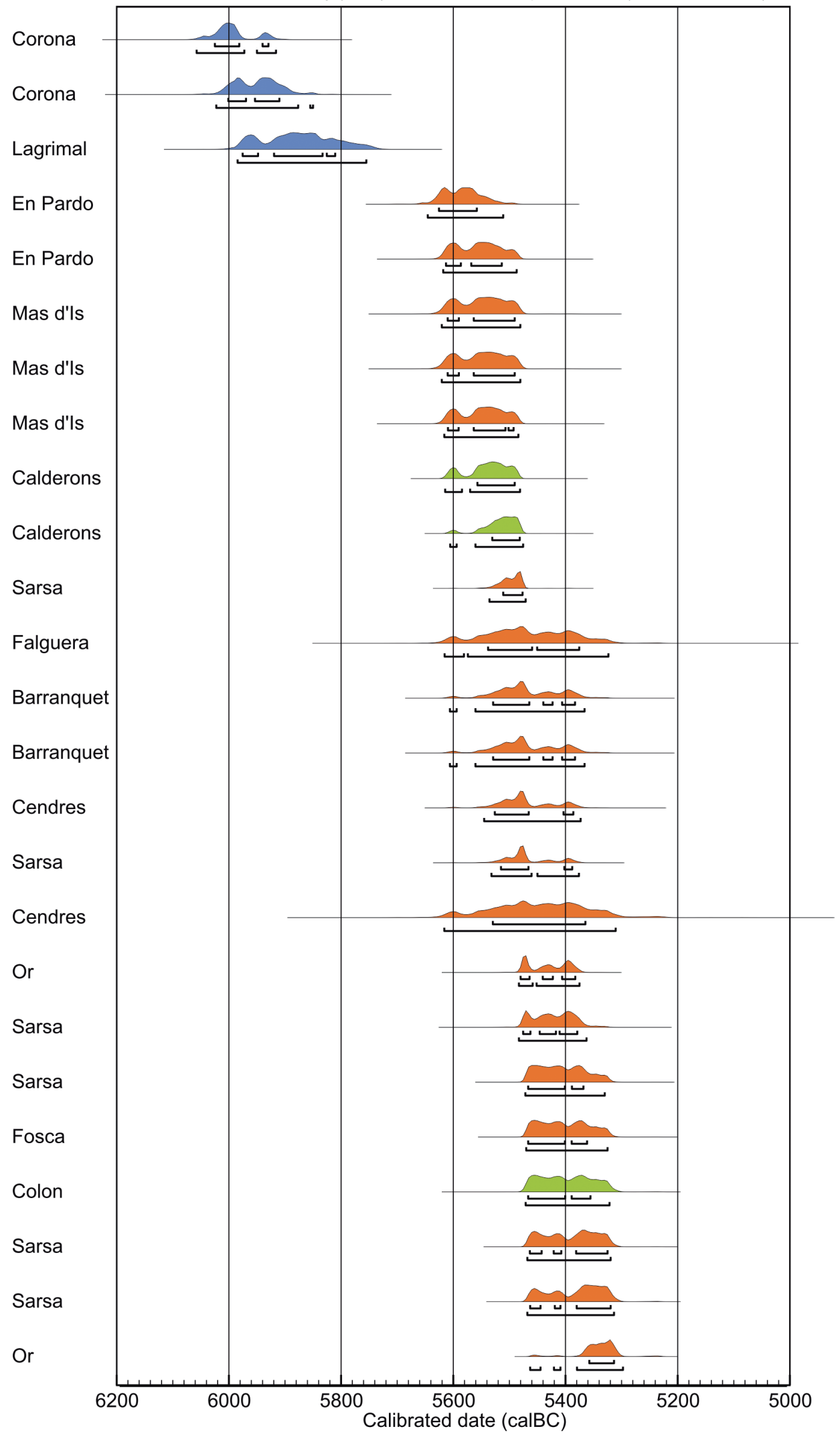

Contextos mesolíticos

Fig. 13. Gráfica comparativa de las dataciones absolutas disponibles de diferentes contextos mesolíticos y neolíticos del ámbito en estudio. / Comparative graph of the absolute dates available from different Mesolithic and Neolithic contexts from the area under study. 
FRANCISCO JAVIER JOVER MAESTRE, PALMIRA TORREGROSA GIMÉNEZ, GABRIEL GARCÍA ATIÉNZAR, MARÍA PASTOR QUILES ALICIA LUJÁN NAVAS, FRANCISCO JAVIER MOLINA HERNÁNDEZ, SEBASTIÁN PÉREZ DÍAZ, MÓNICA RUIZ ALONSO, JOSÉ ANTONIO LÓPEZ SÁEZ, CARLES FERRER GARCÍA y CARMEN TORMO CUÑAT

\begin{tabular}{|c|c|c|c|c|c|c|c|}
\hline YACIMIENTO & CONJUNTO & MUESTRA & REFERENCIA & BP & Cal BC 20 & ADSCRIPCIÓN CULTURAL & BIBLIOGRAFÍA \\
\hline Casa Corona & Enterramiento 2 & Homo sapiens & OxA-V-2392-27 & $7116 \pm 32$ & $6058-5917$ & Mesolítico & $\begin{array}{l}\text { Fernández et al. } \\
2013\end{array}$ \\
\hline Casa Corona & Enterramiento 1 & Homo sapiens & Beta-272856 & $7070 \pm 40$ & $6023-5877$ & Mesolítico & $\begin{array}{c}\text { Fernández et al. } \\
2013\end{array}$ \\
\hline Cueva del Lagrimal & Nivel IV & Capra pyrenaica & Beta-249933 & $6990 \pm 50$ & $5985-5756$ & Mesolítico & $\begin{array}{c}\text { Fernández et al. } \\
2012\end{array}$ \\
\hline Cova d'en Pardo & Nivel VIII inf. & Capra pyrenaica & Beta-231880 & $6660 \pm 40$ & $5646-5512$ & Neolítico antiguo & $\begin{array}{c}\text { García Atiénzar } \\
2009\end{array}$ \\
\hline Cova d'en Pardo & Nivel VIII & Ovis/Capra & Beta-231879 & $6610 \pm 40$ & $5619-5488$ & Neolítico antiguo & $\begin{array}{c}\text { García Atiénzar } \\
2009\end{array}$ \\
\hline Mas d'ls & $\begin{array}{l}\text { UE 80205. Fase } \\
\text { Vib. Casa } 2\end{array}$ & Hordeum vulgare & Beta-166727 & $6600 \pm 50$ & $5621-5481$ & Neolítico antiguo & $\begin{array}{c}\text { Bernabeu et al. } \\
2003\end{array}$ \\
\hline Mas d'ls & $\begin{array}{l}\text { UE } 80219 . \text { Fase } \\
\text { Vla. Casa } 1\end{array}$ & Hordeum vulgare & Beta-162092 & $6600 \pm 50$ & $5621-5481$ & Neolítico antiguo & $\begin{array}{c}\text { Bernabeu et al. } \\
2003\end{array}$ \\
\hline Cova dels Calderons & UE 111 & Ovis aries & Beta-448625 & $6590 \pm 30$ & $5615-5482$ & Neolítico antiguo & \\
\hline Cova dels Calderons & UE 111 & Ovis aries & Beta-446588 & $6560 \pm 30$ & $5606-5476$ & Neolítico antiguo & \\
\hline Cova de la Sarsa & Vestíbulo & Homo sapiens & MAMS-19066 & $6532 \pm 24$ & $5436-5472$ & Neolítico antiguo & $\begin{array}{c}\text { García Borja } \\
2017\end{array}$ \\
\hline Abric de la Falguera & $\begin{array}{l}\text { UE 2051B. } \\
\text { Fase VI }\end{array}$ & $\begin{array}{l}\text { Triticum mono- } \\
\text { coccum }\end{array}$ & Beta-142289 & $6510 \pm 80$ & $5616-5324$ & Neolítico antiguo & $\begin{array}{l}\text { García y Aura } \\
2006\end{array}$ \\
\hline El Barranquet & UE 79 & Ovis aries & Beta-221431 & $6510 \pm 50$ & $5607-5367$ & Neolítico antiguo & $\begin{array}{c}\text { Bernabeu et al. } \\
2009\end{array}$ \\
\hline El Barranquet & UE 79 & Ovis aries & Beta-239379 & $6510 \pm 50$ & $5607-5367$ & Neolítico antiguo & $\begin{array}{c}\text { Bernabeu et al. } \\
2010 \\
\end{array}$ \\
\hline Cova de les Cendres & $\mathrm{H}-19$ & Ovis aries & Beta-239377 & $6510 \pm 40$ & $5546-5374$ & Neolítico antiguo & $\begin{array}{l}\text { Bernabeu y } \\
\text { Molina } 2009\end{array}$ \\
\hline Cova de la Sarsa & Vestíbulo & Ovis aries & OxA-V-26076 & $6506 \pm 32$ & $5533-5377$ & Neolítico antiguo & $\begin{array}{l}\text { García Borja et } \\
\text { al. 2012a }\end{array}$ \\
\hline Cova de les Cendres & $\mathrm{H}-16$ & Triticum dicoccum & GifA-101360 & $6490 \pm 90$ & $5617-5311$ & Neolítico antiguo & $\begin{array}{l}\text { Bernabeu y } \\
\text { Molina } 2009\end{array}$ \\
\hline Cova de I'Or & $\mathrm{VI}$ & Ovis aries & Uci-AMS-66316 & $6475 \pm 25$ & $5484-5376$ & Neolítico antiguo & Martí 2011 \\
\hline Cova de la Sarsa & Vestíbulo & Homo sapiens & MAMS-19068 & $6459 \pm 33$ & $5484-5363$ & Neolítico antiguo & $\begin{array}{c}\text { García Borja } \\
2017\end{array}$ \\
\hline Cova de la Sarsa & Vestíbulo & Ovis aries & OxA-V-26075 & $6420 \pm 32$ & $5472-5331$ & Neolítico antiguo & $\begin{array}{l}\text { García Borja et } \\
\text { al. 2012a }\end{array}$ \\
\hline Cova Fosca & Nivel II & Ovis aries & OxA-26047 & $6413 \pm 33$ & $5471-5326$ & Neolítico antiguo & $\begin{array}{c}\text { García Borja } \\
2012 b\end{array}$ \\
\hline calle Colón & UE 100 & Carbón & Beta-227572 & $6410 \pm 40$ & $5472-5322$ & Neolítico antiguo & $\begin{array}{l}\text { García Atiénzar } \\
\text { et al. } 2006\end{array}$ \\
\hline Cova de la Sarsa & Vestíbulo & Bos taurus & OxA-V-2360-25 & $6399 \pm 33$ & $5469-5320$ & Neolítico antiguo & $\begin{array}{l}\text { García Borja et } \\
\text { al. 2012a }\end{array}$ \\
\hline Cova de la Sarsa & Vestíbulo & Bos taurus & OxA-V-2360-22 & $6389 \pm 34$ & $5469-5314$ & Neolítico antiguo & $\begin{array}{c}\text { García Borja et } \\
\text { al. 2012a }\end{array}$ \\
\hline Cova de I'Or & H3-C6 & Homo sapiens & MAMS-19063 & $6356 \pm 23$ & $5464-5289$ & Neolítico antiguo & $\begin{array}{c}\text { Olalde et al. } \\
2015\end{array}$ \\
\hline
\end{tabular}

Tabla 7: Relación de dataciones absolutas sobre muestras de vida corta (con la excepción de calle Colón) disponibles para las tierras meridionales valencianas, correspondientes al Mesolítico y Neolítico antiguo. / Relation of radiocarbon dates of short life samples available for the southern Valencian region, with the exception of Colón, corresponding to the Mesolithic and early Neolithic.

gueñas, donde se ha documentado la presencia de un horizonte arcaico en la cueva de Nerja fechado en

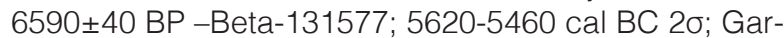
cía Borja et al. 2010; 2018-. En definitiva, la datación en Calderons no contradice el modelo general explicativo de expansión del Neolítico por el Mediterráneo occidental, donde la navegación y el pionerismo fueron fundamentales (Martí 2008). La dificultad reside en que no podemos asociar al resto datado ningún horizonte arcaico, impreso o formativo, similar al propuesto en otros territorios de la península itálica, Golfo de León y del ámbito valenciano, que claramente precede al cardial clásico (Guilaine et al. 2016).

Así pues, hasta la fecha, las evidencias arqueológicas en las tierras alicantinas no permitían considerar la expansión neolítica fuera del territorio cardial (García Atiénzar, 2009) con anterioridad al 5200-5100 cal BC (Jover y García 2014; García Puchol 2017a). Para las 


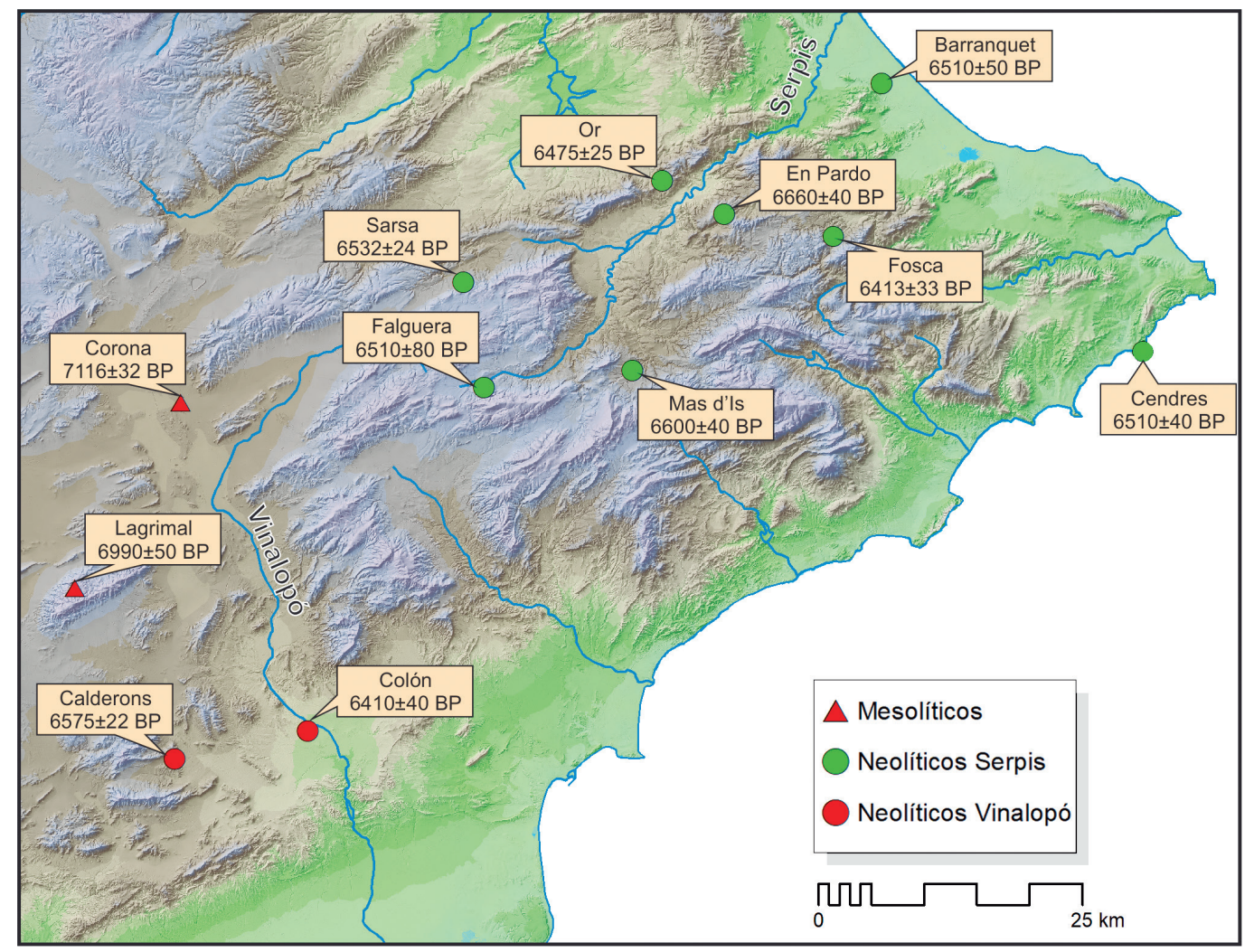

Fig. 14. Mapa con indicación de los principales yacimientos de las cuencas del Serpis y del Vinalopó citados en el texto. / Map indicating the main settlements of the Serpis and Vinalopó basins cited in the text.

comarcas meridionales alicantinas, solamente en el Alto Vinalopó -zona en contacto con las cabeceras del resto de cuencas señaladas- se podría plantear la implantación de las primeras comunidades agropecuarias hacia mediados del VI milenio cal BC. La neolitización del Vinalopó se explicaba como fruto de un largo proceso de segmentación y expansión poblacional, siempre partiendo desde valles próximos como el del Serpis o el Clariano, incluso también desde otros valles cercanos interconectados como el Riu Verd o Montnegre (Jover y García 2015). Sin embargo, y tomando en consideración el marco radiométrico aportado aquí por la Cova dels Calderons, pero también por el de la calle Colón, debemos considerar que este proceso de expansión territorial desde los núcleos iniciales de implantación neolítica tuvo que comenzar antes de lo hasta ahora considerado para el ámbito valenciano.

En este sentido, las dataciones más tardías en relación con los últimos grupos mesolíticos de la cuenca del Vinalopó, procedentes de la cueva del Lagrimal $-6990 \pm 50$ BP- y Casa Corona -7116 \pm 32 BP; 7070 \pm 40 BP- (Fernández et al. 2013; Gómez-Puche et al. 2015), no prolongan la presencia de grupos cazadores recolectores más allá del 5900/5700 cal BC (Figs. 13 y 14). Ya hace unos años, García Puchol (2005: 319) consideró que el Vinalopó podría haber sido un escenario de especial trascendencia para el estudio del contacto entre los últimos mesolíticos y los primeros neolíticos, así como para determinar el proceso de neolitización.
El Vinalopó fue planteado como un posible espacio de "frontera" entre ambas comunidades en el que se pudieron desarrollar procesos de aculturación directa. Con el actual marco radiométrico no podemos confirmar que los primeros grupos neolíticos implantados en las tierras del Serpis y el Clariano llegaran a entrar en contacto con las poblaciones mesolíticas -en su fase B- implantadas en el corredor de Villena, aunque sí podemos comenzar a considerar que los primeros grupos neolíticos en el Vinalopó comenzarían a implantarse hacia mediados del VI milenio cal BC, muy poco después de la desaparición de los últimos mesolíticos.

Por tanto, con los nuevos datos obtenidos de la Cova dels Calderons, se amplían las posibilidades de análisis, abriéndose nuevas líneas de investigación a considerar y desarrollar en el futuro inmediato:

a) La llegada por vía marítima de los primeros contingentes poblacionales con una economía basada en la agricultura y la ganadería a la península ibérica tuvo que producirse un poco antes de lo considerado (Bernabeu et al. 2009; Martins et al. 2015), en torno al 5700-5650 cal BC, con independencia de que posteriormente siguieran llegando nuevos grupos por la misma u otras vías de ingreso. Para el caso de las poblaciones asentadas en el norte de la provincia de Alicante, todos los indicadores materiales permiten establecer una relación directa de origen con poblaciones asentadas en las costas italianas o del Mediterráneo francés (Bernabeu et al. 
2009; García Atiénzar 2010a; García y Jover 2011; Bernabeu y Martí 2014; Bernabeu et al. 2017).

b) Todo indica que los primeros grupos neolíticos que ocuparon las tierras del Vinalopó, en especial las de su cabecera hasta el corredor de Villena -ámbito donde se emplazan los asentamientos mesolíticos de Casa de Lara y Casa Corona (Fernández et al. 2015)-, procederían de valles más septentrionales como el Serpis o el Clariano. Así lo ponen de manifiesto las decoraciones cerámicas advertidas en yacimientos como Arenal de la Virgen (Gómez y Fernández 2016) o la cueva Santa de Caudete (Pérez 1993; García Atiénzar 2010b; Torregrosa y Jover 2016; Martínez Amorós 2018), sin olvidar la presencia de arte esquemático en esta misma cavidad. Los patrones estilísticos del repertorio cerámico de estos dos yacimientos, en especial el segundo (Martínez Amorós 2018) se aproximan a los vistos en Sarsa ${ }^{8}$ (García Borja 2017), lo que permite considerar que el Alto Vinalopó y la cuenca del Clariano pudieron haber sido ocupadas por poblaciones campesinas en un mismo momento.

c) Hacia el sur, se va a producir un cambio significativo por lo que se refiere a la configuración socio-ideológica de las primeras comunidades campesinas y que encuentra en la ausencia de arte rupestre su mejor exponente. Esta ausencia se une a la práctica inexistencia de vasijas con decoración impresa cardial en el Medio y Bajo Vinalopó, algo que también sucede en la cuenca del Segura. Por otra parte, las sintaxis decorativas de los recipientes cerámicos también denotan un cambio significativo, desapareciendo algunas de las composiciones y motivos que habían definido el cardial zonado, y desarrollándose otros, ahora mediante impresión no cardial, exclusivos del Medio y Bajo Vinalopó (Martínez Amorós 2018). Toda esta serie de diferencias en la materialidad debe ser explicada en relación con el proceso histórico que comenzó a gestarse tras su ampliación geográfica hacia otros territorios, y que desembocará en la generación de una nueva realidad sociocultural, fenómeno también documentado en otras regiones del Mediterráneo occidental en momentos inmediatamente posteriores a los de la implantación pionera inicial (Guilaine et al. 2007: 42). Para explicar esta "reformulación" o transformación cultural se han considerado diversas variables a modo de hipótesis, entre las que cabría destacar la relativa importancia de los grupos mesolíticos en la recepción y posterior difusión de las innovaciones neolíticas o la existencia de diferentes puntos de origen con diversos fenómenos de recomposición cultural. Sin embargo, en el caso del Vinalopó, por el momento, no disponemos de datos ni argumentos que permitan considerar ni la coexistencia de cazadores-reco- lectores y grupos agropecuarios en espacios geográficos contiguos, ni la convivencia en un mismo territorio de ambos, así como tampoco la constatación de transferencias materiales por procesos de aculturación directa que permitan argumentar y/o justificar el papel que pudieron jugar los grupos mesolíticos en el proceso de neolitización. Los datos no descartan, por el momento, procesos de exclusión ni tampoco de autoexclusión por parte de los grupos mesolíticos (Jover y García 2014), a pesar de que la distancia temporal entre la desaparición de los primeros y la implantación de los segundos comienza a reducirse considerablemente.

d) Por tanto, en línea con el posible escenario descrito, en nuestra opinión no puede descartarse que las zonas meridionales del Vinalopó -curso Bajo y Medio del Vinalopó y Vega Baja del Segura- pudieran haber sido ocupadas por poblaciones no procedentes necesariamente de las cuencas septentrionales señaladas. No debemos olvidar que la conexión marítima entre el sureste de la península ibérica -hasta el cabo de Santa Pola- y el norte de África es más sencilla que desde el golfo de Valencia y las tierras septentrionales peninsulares, como evidencian las corrientes marinas y los derroteros tradicionales seguidos por los sistemas de navegación en la Antigüedad (Guerrero Ayuso 2007). Por tanto, en las tierras del prelitoral alicantino y murciano pudo haberse dado la confluencia de poblaciones neolíticas de distintos orígenes, llegadas por distintas vías (Fig. 15). Esta hipótesis también ha sido planteada para las tierras meridionales de la península (Manen et al. 2007; Linstädter 2008; Cortes et al. 2012; Isern et al. 2014; Martín Socas et al. 2017), aunque con diferencia de matices. Mientras algunos autores proponen la vinculación entre ambos lados del estrecho de Gibraltar desde momentos iniciales y la vía sur-norte para la propagación del modo de vida neolítico hacia tierras andaluzas y portuguesas (Manen et al. 2007; Marchand y Manen 2010), pudiendo ser Nerja uno de los referentes más antiguos (García Borja et al. 2018), otros autores consideran que esta relación, de haberse dado, nunca pudo haberlo hecho antes del ca. 5350 cal BC y siempre desde las costas septentrionales mediterráneas (Zilhão, 2014). Con todo, somos de la opinión que la explicación meridional, a tenor de los datos disponibles y de la ausencia de elementos diagnósticos materiales, es todavía poco validable para el caso de Calderons y, por extensión, para el Bajo Segura y Bajo Vinalopó, aunque no descartable, siendo necesario considerar una mayor complejidad en el proceso de expansión de las comunidades neolíticas, y abriendo la posibilidad a nuevas vías de difusión que, en cualquier caso, no pueden limitarse a un único evento.

\footnotetext{
${ }^{8}$ Estos dos yacimientos están separados por poco más de $30 \mathrm{~km}$.
} 


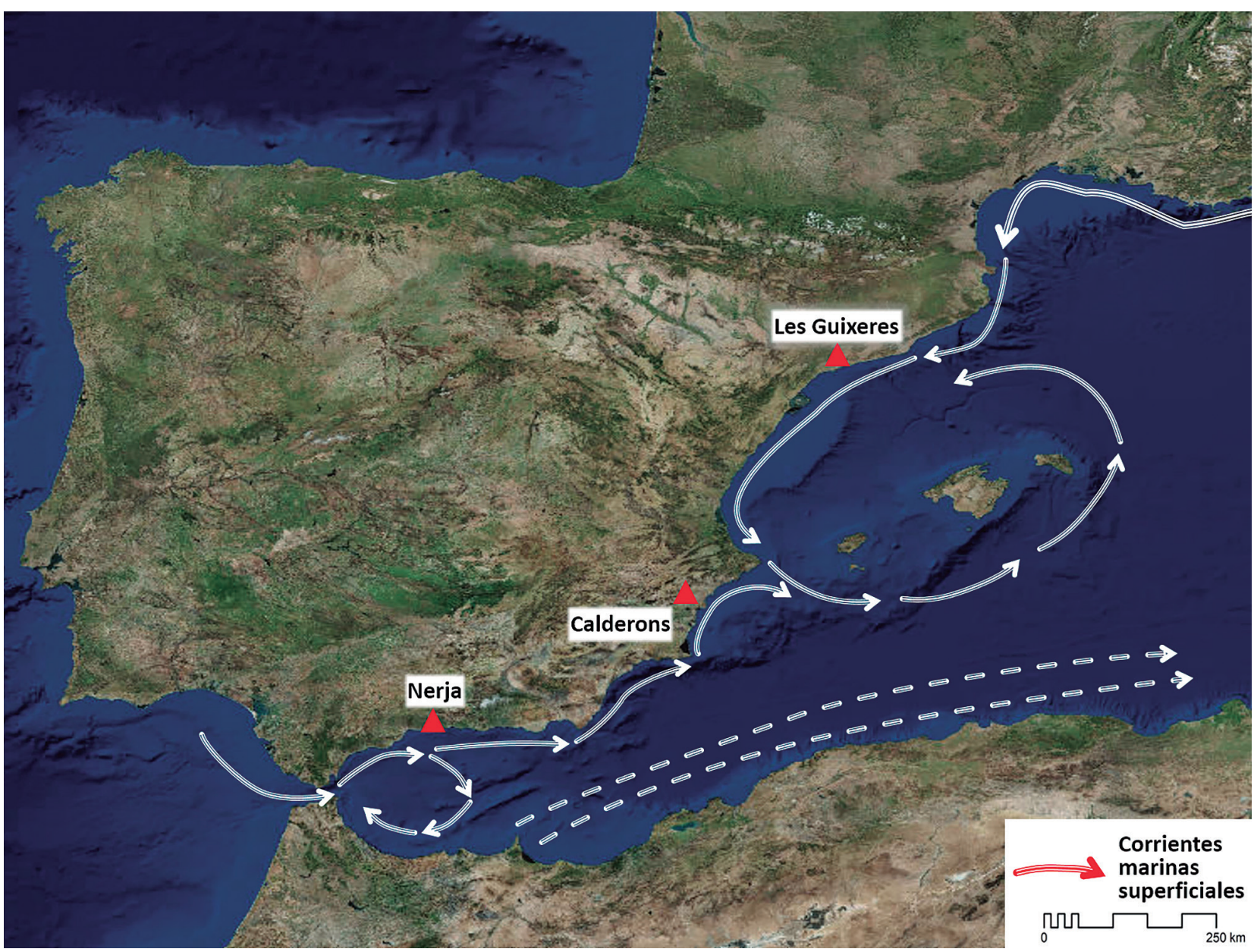

Fig. 15. Mapa con indicación de las principales corrientes y posibles derroteros marinos, en las costas del Sureste peninsular, siguiendo a V.M. Guerrero (2007), con indicación de algunos de los contextos arqueológicos neolíticos datados en las costas malagueñas y catalanas. / Map indicating the main currents and possible sea courses, on the coasts of the Southeast of the Iberian Peninsula, following V.M. Guerrero (2007), with an indication of some of the Neolithic archaeological contexts with dates from the Málaga and Catalan coasts.

e) Por otro lado, al mismo tiempo que aquellos primeros pioneros neolíticos se consolidaban territorialmente en el valle del Serpis en torno al 5600 cal BC, se fueron gestando dos nuevos procesos. Por un lado, el inicio de la expansión territorial hacia otros valles. Este proceso está bien documentado en la cuenca del Júcar a través de la cueva de la Cocina (García Puchol et al. 2017), aunque en este espacio parece producirse en momentos más tardíos, sin que tampoco se pueda determinar el contacto con los grupos mesolíticos habida cuenta del hiato cronológico entre ambas ocupaciones. Para el caso del Vinalopó, y tomando en consideración las dataciones obtenidas en la Cova dels Calderons y c/ Colón, este lapso temporal sería bastante más reducido, abriendo la posibilidad de considerar que el contacto entre ambas formaciones socioeconómicas sí se podría haber llevado a cabo (Jover y García 2014, 2015). En cualquier caso, lo limitado del registro obliga a considerar esta hipótesis solo como una vía de investigación en la que seguir profundizando.
En definitiva, lo aquí aportado no es más que una pequeña prueba que se suma a otros indicios previos. Somos conscientes de que los datos obtenidos proceden de un sondeo y son muy limitados, además de la inexistencia de una cultura material que refrende el dato cronológico. Todavía falta un enorme camino por recorrer, en el que, sin duda, futuras excavaciones aportarán nuevos datos en un sentido u en otro.

\section{BIBLIOGRAFÍA}

Álvarez, E., 2010. Una de cal y otra de arena: Primeras evidencias de explotación de moluscos marinos en la Península lbérica. I Reunión Científica de Arqueomalacología de la Península Ibérica (León 20-21 mayo 2010). Férvedes 6, 95-103.

Barciela, V., García Atiénzar, G., López, E., 2014. El yacimiento prehistórico de Los Limoneros II (Elche). En: Torregrosa, P., Jover, F.J., García Atiénzar, G. (Eds.), El Neolítico en el Bajo Vinalopó (Alicante, España), 51-54. Archaeopress, Oxford. BAR International Series 2646. 
Bernabeu, J., 1989. La tradición cultural de las cerámicas impresas en la zona oriental de la Península Ibérica. Servicio de Investigación Prehistórica, Diputación Provincial de Valencia, Valencia. (Trabajos varios del S.I.P., 86).

Bernabeu, J., 2006. Una visión actual sobre el origen y difusión del Neolítico en la península Ibérica. En: García, O., Aura, J.E. (coords.), El Abric de la Falguera (Alcoi, Alacant). 8000 años de ocupación humana en la cabecera del río de Alcoi, 189211. Alicante.

Bernabeu, J., Lozano, S., Pardo-Gordó, S., 2017. Iberian Neolithic Networks: The Rise and Fall of the Cardial World Frontiers in Digital Humanities 4. https://doi.org/10.3389/fdigh.2017.00007.

Bernabeu, J., Martí, B., 2014. The first agricultural groups in the Iberian Peninsula. En: Manen, C., Perrin, T., Guilaine, J. (Eds.), La transition néolitique en Méditerranée, 419-438. Paris.

Bernabeu, J., Molina, LI., 2009. La cerámica en la secuencia neolítica de Cendres. En: Bernabeu, J., Molina, LI. (Eds.), La Cova de les Cendres (Moraira-Teulada, Alicante), 55-84. Serie Mayor $6 \mathrm{MARQ}$. Alicante.

Bernabeu, J., Molina, LI., 2009. La Cova de les Cendres (Moraira-Teulada, Alicante). MARQ, Alicante. Serie Mayor 6.

Bernabeu, J., Gómez, O., Molina, LI., García, P., 2011. La cerámica neolítica durante el VI milenio cal $\mathrm{AC}$ en el mediterráneo central peninsular. En: Bernabeu, J., Rojo, A.M., Molina, LI. (coords.), Las primeras producciones cerámicas: el VI Milenio cal AC en la Península Ibérica, 153-179. València. Saguntum, Extra-12.

Bernabeu, J. Molina, LI. Esquembre, M.A. Ortega, J.R., Boronat, J.D., 2009. La cerámica impresa mediterránea en el origen del Neolítico de la península Ibérica. En: De Méditerranée et d'ailleurs... Mélanges offerts à Jean Guilaine. Les Archives d'Ecologie Prehistorique, Toulouse. Archives d'Écologie Préhistorique.

Bernabeu, J., Molina, LI., Orozco, T., Diez, A., Barton, C.M., 2008a. Early neolithic at the Serpis Valley, Alicante, Spain. In: Diniz, M., The early neolithic in the Iberian peninsula. Regional ans transregional components, 53-59. Oxford. Bar International series 1857.

Bernabeu, J., Molina, LI., Orozco, T., Diez, A. Michael, C., 2008b. Los valles del Serpis (Alicante): 20 años de trabajo de campo. En: Hernández, M.S., Soler, J., López, J.A. (coords.), IV Congreso del Neolítico peninsular, 50-57. Alicante.

Bernabeu, J., Orozco, T., Díez, A., Gómez, M., Molina, F.J., 2003. Mas d'Is (Penàguila, Alicante): Aldeas y recintos monumentales del Neolítico inicial en el Valle del Serpis. Trabajos de Prehistoria 60(2), 39-59.

Beug, H.J., 2004. Leitfaden der Pollenbestimmung für Mitteleuropa und angrenzende Gebiete. Fisher, Stuttgart.

Boessneck, J., Driesch, A.V.D., 1980. Tierknochenfunde aus vier Südspanischen Höhlen. Studien über frühe Tierknochenfunde von der Iberischen Halbinsel 7, 1-83.

Bottema, S., 1975. The interpretation of pollen spectra from prehistoric settlements (with special attention to liguliflorae). Palaeohistoria 17, 17-35.

Brock, F., Geoghegan, V., Thomas, B., Jurkschat, K., Higham, T., 2013. Analysis of Bone "Collagen" Extraction Products for Radiocarbon Dating. Radiocarbon 55(2), 445-463. https://doi. org/:10.1017/S0033822200057581.
Bronk Ramsey, C., 2017. Methods for Summarizing Radiocarbon Datasets. Radiocarbon 59, Special Issue 6, 1809-1833. https://doi.org/10.1017/RDC.2017.108

Carandini, A., 1997. Historias en la tierra: manual de excavación arqueológica. Crítica, Barcelona.

Cortés, M., Jiménez, F.J., Simón, M.D., Vallejo, M.D., Gibaja, J.F., Carvalho, A.F., Martinez, F., Rodrigo, M., Flores, J.A., Paytan, A., López, J.A., Peña-Chocarro, L., Carrión, J.S., Morales, A., Roselló, E., Riquelme, J.A, Dean, R.M., Salgueiro, E., Martínez, R.M., De La Rubia, J.J, Lozano, M.C., Vera, J.L., Peláez, J.L.. Llorente, L., Bicho, N.F., 2012. The MesolithicNeolithic transition in southern Iberia. Quaternary Research 77, 221-234.

Diot, M.F., 1992. Études palynologiques des blés sauvages et domestiques issus de cultures expérimentales. En: Anderson, P.C. (ed.), Préhistoire de l'agriculture: nouvelles approches expérimentales et ethnographiques, 107-111. Centre de Recherches Archéologiques, Éditions du C.N.R.S, Sophia-Antipolis. Monographie du CRA 6.

Faegri, K., Iversen, J., 1989. Text-book of pollen analysis. 4th. ed. John Wiley \& Sons, Chichester.

Fernández López De Pablo, J., 1999. El yacimiento prehistórico de Casa de Lara, Villena (Alicante). Cultura material y producción lítica. Fundación José María Soler. Villena.

Fernández López de Pablo, J., Gabriel, S., 2016. El Collado shell midden and the explotation patterns of littoral resources during the Mesolithic in the Eastern Iberian Peninsula. Quaternary International 407, 106-117.

Fernández López de Pablo, J., Ferrer, C., Gómez-Puche, M., Tormo, C., Sanchis, A., 2015. Open-air Mesolithic sites in the Central Mediterranean region of Spain: new evidences and research directions. En: Bicho, N., Detry, C., Douglas Price, T., Cunha, E. (eds.), Muge 150th: the 150th anniversary of the discovery of Mesolithic shellmiddens, vol 2, 75-92. Cambridge.

Fernández López de Pablo, J., Salazar, D.C., Subirà, M.E., Roca de Togores, C., Gómez, M., Richards, M.P., Esquembre, M.A., 2013. Late mesolithic burials at Casa Corona (Villena, Spain): direct radiocarbon and palaeodietary evidence of the last forager populations in Eastern iberia. Journal of Archaeological Science 40, 671-680.

Fortea, J., 1973. Los complejos microlaminares y geométricos del Epipaleolítico mediterráneo español. Salamanca.

Gállego, I.C., García de Domingo, A., López Olmedo, F., 1984. Mapa geológico de España. E: 1:50.000. Pinoso. Servicio de Publicaciones Ministerio de Industria y Energía. Madrid.

García Atiénzar, G., 2009. Territorio neolítico. Las primeras comunidades campesinas en la fachada oriental de la península Ibérica (5600-2800 cal BC). Archaeopress, Oxford. BAR International series 2021

García Atiénzar, G., 2010a. Las comarcas centromeridionales valencianas en el contexto de la Neolitización de la fachada noroccidental del Mediterráneo. Trabajos de Prehistoria 67(1), 37-58. https://doi.org/10.3989/tp.2010.10030.

García Atiénzar, G., 2010b. El yacimiento de Fuente de Isso (Hellín) y el poblamiento neolítico en la provincia de Albacete. Instituto de Estudios Albacetenses. Diputación Provincial de Albacete, Albacete

García Atiénzar, G., 2012. Las sociedades tribales durante el neolítico inicial en el mediterráneo occidental: procesos de expansión y consolidación durante el VI milenio cal BC. Boletín de Antropología Americana 47, 101-120. 
García Atiénzar, G., Jover, F.J., 2011. The introduction of the first farming communities in the western Mediterranean: the valencian region in Spain as example. Arqueología Iberoamericana 10, 17-29

García Atiénzar, G., Jover, F.J., Ibáñez, C., Navarro, C., Andrés, D., 2006. El yacimiento neolítico de la calle Colón (Novelda, Alicante). Recerques del Museu d'Alcoi 15, 19-28.

García Borja, P., 2017. Las cerámicas neolíticas de la Cova de la Sarsa (Bocairent, Valencia). Tipología, estilo e identidad. Servicio de Investigación Prehistórica, Diputación Provincial de Valencia, Valencia. (Trabajos varios del S.I.P., 120).

García Borja, P., Aura, J.E., Bernabeu, J., Jordà, J.F., 2010. Nuevas perspectivas sobre la neolitización den la cueva de Nerja (Málaga, España). La cerámica de la sala del vestíbulo. Zephyrus 66, 109-132.

García Borja, P., Cortell, E., Pardo, S., Pérez, G., 2011a. Las cerámicas de la cova l'Or (Beniarrés, Alacant). Tipología y decoración de las colecciones del Museu d'Alcoi. Recerques del Museu d'Alcoi 20, 71-136.

García Borja, P., Salazar, D.C., Aura, E., Cortell, E., Velasco, A., 2016a. El registro funerario cardial valenciano: dataciones radiocarbónicas. Del neolític a l'edat del bronze en el Mediterrani occidental. Estudis en Homenatge a Bernat Martí Oliver. Serie de Trabajos Varios 119, 125-140.

García Borja, P., Salazar, D., Collado, I., Cortell, E., 2016b. Los restos humanos de la Coveta Emparetà: contexto cronológico y cultural. Recerques del Museu d'Alcoi 25, 31-46.

García Borja, P., Salazar, D., Pérez, A., Pardo, S., Casanova, V., 2011b. El Neolítico antiguo cardial y la Cova de la Sarsa (Bocairent, València). Nuevas perspectivas a partir de su registro funerario. Munibe Antropologia-Arkeologia 62, 175-195.

García Borja, P., Salazar, D.C., Jordá, J.F., Pérez Ripoll, M. Aura, J.E., 2018. El inicio del Neolítico en la cueva de Nerja y la Cova de la Sarsa. Contexto arqueológico y dataciones radiocarbónicas. Pyrenae 49(2), 7-36.

García Esteban, L., de Palacios, P., Guindeo, A., García, L, Lázaro, I., González, L., Rodríguez, Y., Fernández, F., Bobadilla, I., Camocho, A., 2002. Anatomía e identificación de maderas de coníferas a nivel de especie. Fundación Conde del Valle de Salazar. Ediciones Mundi-Prensa, Madrid.

García Puchol, O., 2005. El proceso de neolitización en la fachada mediterránea de la península Ibérica. Tecnología y tipología de la piedra tallada. Archaeopress, Oxford. BAR International Series 1430

García Puchol, O., Aura, J.E., 2006. El abric de la Falguera (Alcoi, Alacant) 8.000 años de ocupación humana en la cabecera del río de Alcoi. Ajuntament d'Alcoi. MARQ, Alicante.

García Puchol, O., Díez, A., Pardo, S., 2016. Radiocarbono y neolitización en la península lbérica". Del neolític a l'edat del bronze en el Mediterrani occidental. Estudis en Homenatge a Bernat Martí Oliver. Serie de Trabajos varios del SIP, 119, 6174. Valencia.

García-Puchol, O., Bernabeu, J., Barton, C., Pardo-Gordó, S. Mcclure, S., Diez, A., 2018. A Bayesian Approach for Timing the Neolithization in Mediterranean Iberia. Radiocarbon, 60(1), 181-205. https://doi.org/10.1017/RDC.2017.61.

García-Puchol, O., Mcclure, S.B., Juan-Cabanilles, J., Diez, A., Bernabeu, J., Martí, B., Pardo-Gordó, S., Pascual, J.L., Pérez, M., Molina, LI., Kennett, D.J., 2017. Cocina cave revisited: Bayesian radiocarbon chronology for the last hunter-gatherers and first farmers in Eastern Iberia. Quaternary International 471, Part B, 259-271. https://doi.org/10.1016/j.quaint.2016.10.037.

García-Puchol, O., Salazar, D.C., 2017. Times of Neolithic transition along the Western Mediterranean. Springer. Fundamental Issues in Archaeology. Available at: https://doi. org/10.1007/978-3-319-52939-4_1

Gómez-Puche, M., Fernández-López de Pablo, J., 2015. AMS radiocarbon chronology of Late mesolithic sites in the Upper Vinalopó River (Eastern Iberia). In: Bicho, N., Detry, C., Douglas Price, T., Cunha, E. (eds.), Muge 150th: the 150th anniversary of the discovery of Mesolithic shellmiddens vol 2, 125-138. Cambridge.

Gómez-Puche, M., Fernández-López De Pablo, J., 2016. El yacimiento neolítico del Arenal de la Virgen (Villena, Alicante): estudio de la colección de materiales de José María Soler. Bilyana 1, 17-30.

Grimm, E.C., 1992. Tilia, version 2, IL 62703, USA. Illinois State Musseum, Research and Collection Center, Springfield.

Grimm, E.C., 2004. TGView. Illinois State Museum, Springfield.

Guerrero, V.M. (coord.), 2007. Prehistoria de las islas Baleares. Registro arqueológico y evolución social antes de la Edad del Hierro. Archaeopress. Oxford. BAR International Series 1690.

Guilabert, A.P., Hernández, M.S., 2014. La Cova de Les Aranyes (o del Frare) del Carabassí (Santa Pola). En: Jover, F.J., Torregrosa, P., García, G. (eds.), El Neolítico en el Bajo Vinalopó, 55-92. Archaeopress, Oxford. BAR International Series 2646.

Guilabert, A.P., Jover, F.J., Fernández, J., 1999. Las primeras comunidades agropecuarias del Río Vinalopó (Alicante). II Congrés del Neolític a la Península Ibèrica, 283-290. Valencia. Saguntum-PLAV, Extra-2, 283-290. Valencia.

Guilaine, J., Manen, C., Vignè J.D., 2007. Pont de Roque-Haute. Noveaux regards sur la neolithisation de la France Méditerranéene. Toulouse. Archives d'Écologie Préhistorique-Societé Préhistorique Française.

Guilaine, J., Metallimou, G., Berger, J.F., 2016. La néolithisation de la Méditerranée occidentale: sur la piste des pionniers? Del neolític a la Edat del Bronze en el Mediterrani occidental. Estudis en Homenatge a Bernat Martí Oliver. Serie de Trabajos Varios del SIP, 119, 27-34. Valencia.

Harris, E., 1991. Principios de estratigrafía arqueológica. Crítica, Barcelona.

Hather, J.G., 2000. The identification of the Northern European woods. A guide for archaeologists and conservators. Archetype Publications, Londres.

Hernández, M.S., Soler, J.A., Guilabert, A., Benito, M., 2012. La Cova de les Aranyes del Carabassí. Distintas carpetas de una investigación imprescindible para el conocimiento de la Prehistoria del litoral meridional de Alicante. En: Sánchez, M.J. (coord.), Santa Pola. Arqueología y Museo, 102-119. Museos municipales en el MARQ, Alicante.

Iborra, M.P., Martínez-Valle, R., 2009. La fauna de los niveles neolíticos de la Cova de les Cendres. En: Bernabeu, J., Molina, LI. (Ed.), La Cova de les Cendres (Moraira-Teulada, Alicante), 149-162. MARQ, Alicante. Serie Mayor 6. Alicante.

Isern, N., Fort, J., Carvalho, A.F, Gibaja, J.F., Ibáñez. J.J., 2014. The Neolithic transition in the Iberian Peninsula: data analysis and modeling. Journal of Archaeological Method and Theory 21, 447-460.

Jover, F.J., García, G., 2014. Sobre la neolitización de los grupos mesolíticos en el este de la península Ibérica: la exclusión como posibilidad. Pyrenae 45(1), 55-88. 
Jover, F.J., García, G., 2015. Sociedades en transición durante la expansión y consolidación de las primeras comunidades agrícolas en el Mediterráneo occidental: el ejemplo del Levante de la península Ibérica. Vegueta 15, 133-157.

Jover, F.J., Torregrosa, P., García, G., 2014. El Neolítico en el Bajo Vinalopó (Alicante, España). Oxford. BAR International Series 2646.

Juan Cabanilles, J., 2009. El utillaje de piedra tallada en la Prehistoria reciente valenciana. Aspectos tipológicos, estilísticos y evolutivos. Servicio de Investigación Prehistórica. Diputación Provincial de Valencia, Valencia. (Serie de Trabajos Varios del SIP 109).

Linstädter, J., 2008. The Epipalaeolithic-Neolithic Transition in the Mediterranean region of Northwest-Africa. Quartär 55, 41-62.

López Sáez, J.A., López Merino, L., 2005. Precisiones metodológicas acerca de los indicios paleopalinológicos de agricultura en la Prehistoria de la Península Ibérica. Portugalia 26, 53-64

López Sáez, J.A., Van Geel, B., Farbos-Texier, S., Diot, M.F., 1998. Remarques paléoécologiques à propos de quelques palynomorphes non-polliniques provenant de sédiments quaternaires en France. Revue de Paléobiologie 17(2), 445-459.

López Sáez, J.A., van Geel, B., Martín Sánchez, M., 2000. Aplicación de los microfósiles no polínicos en Palinología Arqueológica. In: Oliveira Jorge, V. (coord.), Contributos das Ciências e das Technologias para a Arqueologia da Península Ibérica. Actas $3^{\circ}$ Congresso de Arqueologia Peninsular vol. IX, Vila-Real, Portugal, setembro de 1999, 11-20. Adecap, Porto.

López Sáez, J.A., López García, P., Burjachs, F., 2003. Arqueopalinología: Síntesis crítica. Polen 12, 5-35.

Luján, A., 2004. La malacofauna. En: Torregrosa, P., López, E. (eds.), La Cova de San Martí, Agost (Alicante), 77-85. Diputación Provincial de Alicante y Ayuntamiento de Agost. Memorias Excavaciones Arqueológicas 3.

Luján, A., 2016. Aprovechamiento y gestión de recursos malacológicos marinos en la fachada mediterránea de la península Ibérica durante la Prehistoria reciente. Tesis doctoral. Universidad de Alicante. Disponible en:http://hdl.handle. net/10045/60838 (fecha consulta: 21 de abril de 2018).

Luján, A., Rosser, P., 2013. La malacofauna marina en el yacimiento neolítico del Tossal de les Basses (Albufereta, Alicante). En: Sanchís, A., Pascual, J. LI. (coords.), Animals i arqueologia hui.: I Jornades d'Arqueozoologia del Museu de Prehistòria de València, 235-256. Valencia.

Manen, C., Marchand, G., Carvalho, A.F., 2007. Le Néolithique ancien de la péninsule Ibérique: vers une nouvelle évaluation du mirage africain? Actes du XXVle Congrès Préhistorique de France (Avignon 2004), 133-151

Marchand, G., Manen, C., 2010. Mésolithique final et Néolithique ancien autour du détroit: une perspective septentrionale (Atlantique/Méditerranée). In: Gibaja, J.F., Carvalho, A.F. (eds.), Os últimos caçadores-recolectores e as primeiras comunidades produtoras do sul da Península Ibérica e do norte de Marrocos, 173-179. Universidade do Algarve, Faro.

Martí, B. 1977. Cova de L'Or (Beniarrés, Alicante) Vol. I. Serie Trabajos Varios del Servicio de Investigación Prehistórica 51. Diputación de Valencia, Valencia.

Martí, B., 2008. Cuevas, poblados y santuarios neolíticos: una perspectiva mediterránea. IV Congreso del Neolítico peninsular volumen II, 17-27. Alicante.
Martí, B., Aura, J.E., Juan, J., García, O., Fernández, J., 2009. El Mesolítico geométrico de tipo "Cocina" en el País Valenciano. El Mesolítico Geométrico en la península Ibérica (Jaca, 2009), 205-258. Jaca. Monografías arqueológicas 44.

Martí, B., Pascual, V., Gallart, M.D., López, P., Pérez, M., Acuña, J-D., Robles, F., 1980. Cova de l'Or (Beniarrés, Alicante). Vol. II. Trabajos Varios del Servicio de investigación Prehistórica 65. Valencia

Martín-Socas, D., Camalich, M.D., Caro, J.L. y Rodríguez, F.J., 2017. The beginning of the Neolithic in Andalusia. Quaternary International 470, 451-471. http://dx.doi.org/10.1016/j. quaint.2017.06.057.

Martínez Amorós, S., 2018. El estilo decorativo en las primeras producciones cerámicas en el valle del río Vinalopó (Alicante). Panta Rei: Revista Digital de Ciencia y Didáctica de la Historia, 9-32. https://doi.org/10.6018/pantarei/2018/1

Martins, H., Oms, F.X., Pereira, L., Pike, A. W.G., Rowsell, K., Zilhão, J., 2015. Radiocarbon dating the beginning of the Neolithic in Iberia: New Results, new problems. Journal of Mediterranean Archaeology 28(1), 105-131.

Molina Hernández, F.J., 2001. Análisis del poblamiento en el área oriental de las comarcas de l'Alcoià y El Comtat durante el Neolítico I a partir de la localización de nuevos yacimientos al aire libre (Alicante). Bolskan 18, 195-205.

Molina, F.J., 2016. El sílex del Prebético y Cuencas Neógenas en Alicante y Sur de Valencia. Su caracterización y estudio aplicado al Paleolítico Medio. Tesis Doctoral, Universidad de Alicante. Disponible en: http://hdl.handle.net/10045/56446.

Moore, P.D., Webb, J.A., Collinson, M.E., 1991. Pollen Analysis, Blackwell Scientific Publications, London.

Oms, F. X., Esteve, X., Mestres, J., Martín, P., Martins, H., 2014. La neolitización del nordeste de la Península Ibérica: datos radiocarbónicos y culturales de los asentamientos al aire libre del Penedés. Trabajos de Prehistoria 71(1), 43-56. http://dx. doi.org/10.3989/tp.2014.12123.

Orozco, T., 2016. Los brazaletes de esquisto: un elemento de la identidad cardial. Del neolític a l'edat del bronze en el Mediterrani occidental. Estudis en homenatge a Bernat Martí Oliver. Servicio de Investigación Prehistórica del Museo de Prehistoria de Valencia. Diputación Provincial de Valencia. Serie de Trabajos Varios del SIP 119, 141-146. Valencia.

Papí, C., 1989, Los elementos de adorno-colgantes en el Paleolítico Superior y Epipaleolítico: pautas para su estudio tecnológico. Trabajos de Prehistoria 46, 47-63.

Pardo-Gordó, S., Díez, A., Bernabeu, J., And Chaos, V., Molina Balaguer, LI., Barton, M.Ch., 2015. Prospecciones sistemáticas en la Depressió de l'Alcoi (Alacant): analizando las colecciones superficiales. $5^{\circ}$ Congresso do Neolítico Peninsular: Actas: Faculdade de Letras da Universidade de Lisboa, (7-9 abril 2011), 397-404. Lisboa.

Pascual Benito, J. LI., 1994. El utillaje óseo. Los adornos. La malacofauna y las manifestaciones religiosas de Niuet. En: Bernabeu, J., Pascual-Benito, J. LI., Orozco, T., Badal, E., Fumanal, M.P., García Niuet, O. (L'Alqueria d'Asnar): Poblado del III Milenio a.C., 83-98. Alcoi. Recerques del Museu d'Alcoi 3.

Pérez Amorós, M.L., 1993. El yacimiento neolítico de la Cueva Santa (Caudete). Revista de Fiestas de Moros y Cristianos. Caudete.

Pérez Ripoll, M., 1980. La fauna de vertebrados. En: Martí, B., Pascual, V., Gallart, M.D., López, P., Pérez, M., Acuña, J.D., 
Robles, F., La Cova de l'Or (Beniarres, Alicante),193-255. Diputació Provincial de València, València. Vol. II. Trabajos Varios del SIP 65. Valencia.

Pérez Ripoll, M., 2006. Las evidencias de una orientación ganadera. Los datos. En: García Puchol, O., Aura, J.E. (coords), El Abric de la Falguera (Alcoi, Alacant). 8000 años de ocupación humana en la cabecera del río de Alcoi, 219-255. Ajuntament d'Alcoi, Diputació Provincial d'Alacant, C.A.M. Alcoi.

Reille, M., 1999. Pollen et spores d'Europe et d'Afrique du Nord. Laboratoire de Botanique Historique et Palynologie, Marseille.

Reimer, P.J., Bard, E., Bayliss, A., Beck, J.W., Blackwell, P.G., Bronk Ramsey, C., Buck, C. E., Cheng, H., Edwards, R.L., Friedrich, M., Grootes, P.M., Guilderson, T.P., Haflidason, H. Hajdas, I., Hatté, C., Heaton, T.J., Hoffmann, D.L., Hogg, A.G., Hughen, K.A., Kaiser, K.F., Kromer, B., Manning, S.W., Niu, M., Reimer, R.W., Richards, D.A., Scott, E.M., Southon, J. R. Staff, R.A., Turney, C.S.M., Van Der Plicht, J., 2013. IntCal13 and Marine13 Radiocarbon Age Calibration Curves 0-50,000 Years cal BP. Radiocarbon, 55(4), 1869-1887. https://doi. org/10.2458/azu_js_rc.55.16947.

Rico, L.,y Cantarino, C., 1989. Malacofauna. En: Azuar Ruíz, R., La Rábita Califal de las dunas de Guardamar (Alicante), 163-173. Memorias de excavaciones arqueológicas, Alicante.

Ruíz, M., 1999. Los artefactos y arteusos malacológicos de Gatas. En: Castro, P., Chapman, R., Gili, S., Lull, V., Micó, R., Rihuete, C., Richs, R., Sanahuja, M.E. (eds.), Proyecto Gatas 2. La dinámica arqueológica de la ocupación prehistórica, 361 387. Sevilla. Arqueología Monografías 4.

Schweingruber, F.H., 1978. Mikroskopische holzanatomie Züricher A. G., Zug.

Schweingruber, F.H., 1990. Anatomie europäischer Hölzer: ein Atlas zur Bestimmung europäischer Baum-, Strauch- und Zwergstrauchhölzer. Verlag P. Haupt, Bern.

Segura, G., Jover, F.J., 1997. El poblamiento prehistórico en el Valle de Elda (Alicante). Petrer. Colecció l'Algoleja 1.

Soler Díaz, J., 2002. Cuevas de inhumación múltiple en la Comunidad Valenciana. Real Academia de la Historia, Museo Arqueológico Provincial de Alicante, Alicante.

Soler Díaz, J., López Padilla, J.A., 2000/2001. Nuevos datos sobre el poblamiento entre el neolítico y la Edad del Bronce en el sur de Alicante. Lvcentum XIX-XX, 7-25.

Soler Díaz, J.A. (coord.), 2012. Cova d'En Pardo: arqueología en la memoria: excavaciones de M. Tarradell, V. Pascual y E. Llobregat (1961-1965), catálogo de materiales del Museo de Alcoy y estudios a partir de las campañas del MARQ (19932007) en la cavidad de Planes, Alicante. Fundación C.V. MARQ, Alicante. Ayuntamiento de Alcoi.

Soler Díaz, J.A., Duque, D., Ferrer, C., Gómez, O., Guillem, P.M., Iborra, P., Martínez, R., Pérez, G., Roca De Togores, C., Ximénez De Embún, T., 2013. Sobre el significado de la primera ocupación neolítica de la Cova d'en Pardo (Planes, Alicante): avance de estudio pluridisciplinar de los niveles VIII y VIIIb. Saguntum (P.L.A.V.) 45, 9-24.

Taborín, Y., 1974. La parure en coquillage de I’Epipaléolithique au Bronze Ancien en France. Gallia Prehistoire 101-179, 308-417.

Torregrosa, P., Jover, F.J., 2016. La Cova dels Calderons (La Romana, Alicante) y los inicios del Neolítico en el valle del Vinalopó. Archivo de Prehistoria Levantina XXXI, 87-117.
Torregrosa, P., López, E., 2004. La Cova Sant Martí (Agost, Alicante). Series Excavaciones Arqueológicas, Memorias, 3. Museo Arqueológico Provincial (MARQ), Diputación Provincial de Alicante y Excmo. Ayuntamiento de Agost.

Torregrosa, P., Jover, F.J., López, J., 2011. Benàmer (Muro de Alcoi, Alicante): Mesolítico y neolíticos en las tierras meridionales valencianas. Museu de Prehistòria de València, Diputación de Valencia. Serie Trabajos Varios del SIP 112, Valencia.

Van Geel, B., 2001. Non-pollen palynomorphs. En: Smol, J.P., Birks, H.J.B., Last, W.M. (eds.), Tracking environmental change using lake sediments, volume 3, 99-119. Terrestrial, algal and silicaceous indicators, Kluwer Academic Publishers, Dordrecht.

Van Klinken, G.J., 1999. Bone collagen quality indicators for palaeodietary and radiocarbon measurements. Journal of Archaeological Science 26(6), 687-695.

Vernet, J.L., Ogereau, P., Figueriral, I., Machado, C., Uzquiano, P., 2001. Guide d'identification des charbons de bois préhistoriques et récents. Sud-Ouest de l'Europe: France, Péninsule Ibérique et Îles Canaries. CNRS Éditions, París.

Zeder, M.A., Lapham, H.A., 2010. Assessing the reliability of criteria used to indentify postcranial bones in sheep, Ovis, and goats, Capra. Journal of Archaeological Science 27, 28872905.

Zilhão, J., 1993. The Spread of Agro-Pastoral Economies across Mediterranean Europe: A View from the Far West. Journal of Mediterranean Archaeology 6, 5-63.

Zilhão, J., 2001. Radiocarbon evidence for maritime pioneer colonization at the origins of farming in West Mediterranean Europe. Proceedings of the National Academy of Sciences 98, 14180-14185

Zilhão, J., 2014. Early prehistoric navigation in the Western Mediterranean: implications for the neolithic transition in Iberia and the Maghreb. Eurasian Prehistory 11 (1-2), 185-200. 
